\title{
Modeling the Evolution of Residual Stresses in Thermally Sprayed YSZ Coating on Stainless Steel Substrate
}

\author{
Ahmed Fardan $^{1} \cdot$ Rehan Ahmed ${ }^{1}$
}

Submitted: 9 May 2018/in revised form: 1 March 2019/Published online: 2 April 2019

(C) The Author(s) 2019

\begin{abstract}
This study is based on Eulerian method to model residual stresses for yttrium-stabilized zirconia coating applied to stainless steel substrate. A commercially available finite element software ABAQUS/Explicit is used to conduct this study. Single and multiple-particle impact analyses were carried out, and the residual stress data have been reported. The analysis is performed for two different values of thermal contact resistance and the throughthickness residual stress profiles obtained within the coating for single particle are tensile, while the substrate has a mixture of tensile and compressive residual stresses. For multiple impact model, the residual stress data have been presented for substrate with and without cooling. The residual stresses within the coating without substrate cooling are mostly tensile while the substrate is compressive. The residual stresses within the coating with substrate cooling are mostly tensile with compressive stresses on the top of the coating, while the substrate consists of compressive stresses. The obtained residual stresses are compared with experimental and analytical data.
\end{abstract}

Keywords ABAQUS · Eulerian · finite element modeling · heat transfer - residual stress · solidification - thermal spray

Rehan Ahmed

r.ahmed@hw.ac.uk

Ahmed Fardan

af212@hw.ac.uk

1 School of Engineering and Physical Sciences, Heriot-Watt University, Edinburgh EH14 4AS, UK

\section{Introduction}

Thermal spray technology comprises a group of coating processes in which finely divided metallic or nonmetallic particles are deposited in molten or semi-molten condition to form a coating. The coating material may be in the form of powder, ceramic rod, wire or molten material. For plasma spraying, the particle is heated up to or above its melting point and is made to impact the substrate at moderate velocity $(100-300 \mathrm{~m} / \mathrm{s})($ Ref 1$)$. The invention of thermal spray credit goes to MU Schoop (1911), who received patents along with several collaborators to commercialize the process (Ref 1). The need for coatings has increased over the past few years since it improves functional performance; reduces wear due to abrasion, erosion and corrosion; extends the component life by rebuilding the worn part; and reduces cost by applying expensive coating over cheaper material (Ref 1-7). Understanding of lamella bonding, formation of microstructural features and residual stresses in the finished parts are some of the technological challenges. This paper deals with the evolution of residual stresses of YSZ particle from the point of impact of lamella particle until it has cooled down as the building block of coating microstructure.

To achieve uniform properties in thermally sprayed components, it requires careful control of particle diameter, particle impact velocity and temperature. It is cost-effective to optimize the operating parameters using computational methods rather than experiments due to the high operational costs of the experiment. The first experimental observations of droplet impacting substrate were performed by Worthington Ramsden (1903) (Ref 8). Worthington observed and recorded the splashing and fingering of milk and mercury droplets impacting a smooth substrate. The first known numerical modeling of splashing of liquid drop 
was performed by Harlow and Shannon (1967) using Marker and Cell technique (MAC) (Ref 9). With the development of computing power, computational methods have been widely used to model thermal spray droplet impact.

Table 1 represents some of the particle and substrate parameters obtained from the literature for various droplet impact models. Most of the thermal spray droplet impact models available in the literature deal with heat transfer, solidification, formation of pores etc. while not dealing with evolution of residual stresses. Lagrangian, smoothed particle hydrodynamics (SPH), Eulerian, coupled EulerianLagrangian (CEL) and computational fluid dynamics (CFD) are some of the methods employed to model droplet impact. Previously, Lagrangian method was employed to model cold spray coatings, and some of the works can be found in (Ref 10-14). The drawbacks of using Lagrangian method are that the model is mesh-sensitive (requires fine mesh and increases calculation time), rebound of particles during multiple-particle impact and above a certain particle velocity, the program terminates due to excessive distortion of elements. Mesh regeneration in this case is of limited use as the distorted mesh is also on the contact surface, and contact mechanics algorithm overrides mesh distortion. SPH is a mesh-free method which is suitable to model high distortion spray process (Ref 10), works presented in (Ref 15-17) are modeled using SPH method. Additionally, SPH is able to overcome the rebound phenomenon experienced in Lagrangian method (Ref 10). Recently, Eulerian method has been widely used to model droplet impact and some of the works can be found in Ref 10, 11. The numerical models using Eulerian methods were more comparable to the experimental observations than the Lagrangian model approach, and hence, Eulerian method is widely used to model single and multiple impact thermal spray processes (Ref 10). Eulerian mesh allows the material to flow within the fixed grid and is suitable to model fluids and molten materials. The combination of Eulerian and Lagrangian is known as CEL (coupled Eulerian-Lagrangian) and it overcomes the above-mentioned disadvantages. Earlier computational models focused on particle diameter of $2-5 \mathrm{~mm}$ and particle velocity of $1-5 \mathrm{~m} / \mathrm{s}$ for the ease of comparison with experiments. In reality, the particle diameter is in the order of micrometers $(10-60 \mu \mathrm{m})$ and the impact velocity is around 100-300 m/s (Ref 18-22).

The most advanced finite element simulation for unmelted solid particles impact can be found in Ref 11 for copper particle impacting copper substrate. Due to the limited computational resources, some of the earlier works presented in Ref 3, 18, 23 are limited to $2 \mathrm{D}$ axisymmetric simulations which hinders the extent of the study that can be performed on the models, such as the splat morphology of the droplets deposited. With further development of faster processing machines and advancement in simulation software, 3D models were widely published and some of them can be found in Ref 20, 21, 24-26. A sequential droplet impingement analysis was carried out in Ref 20 where formations of detached rings were reported, which were caused due to the momentum gained by the impact of the second droplet. This also led to fragmentation (satellite droplets). While the work presented in Ref 24 looks at the number of fingers caused when a droplet impacts a surface using Rayleigh-Taylor (RT) instability theory, the computational results were in good agreement with experimental results. The study of heat transfer and solidification are crucial elements for the study of splat morphology and some of the works can be found in Ref 21, 26. The work presented by Fard et al. (Ref 26) studied the heat transfer of a tin droplet impacting stainless steel substrate and performed experiments to validate their results. The work presented in Ref 21 extends the work done in Ref 26, by studying the heat transfer of normal and incline impact. Experimental and numerical simulation of single and multiple Nickel particle impacting stainless steel substrate was performed by Fard et al. (Ref 27) while including the effect of heat transfer and solidification for the simulations. Observations of splashing were recorded from the experimental observations for Nickel particles impacting stainless steel substrate for substrate temperature of $563 \mathrm{~K}$ while no splashing was observed for substrate temperature of $673 \mathrm{~K}$. However, in numerical simulations increasing the substrate temperature didn't make much of a difference in splat morphology but increasing the thermal contact resistance drastically changed the morphology. Another notable assumption by Xue et al. was that the thermal contact resistance value need not be provided to the model, it can be varied through substrate roughness and thermal conductivity (Ref 28). Although different modeling techniques and advancement in computational efficiency have significantly improved the splat modeling in thermal spray coatings, the technological challenge of fine-tuning the material parameters such as very high strain rates, work hardening, high cooling rates and temperature-dependent physical parameters require further work. This coupled with challenges in attaining experimental data which is predominantly limited to post-deposition process makes the validation of the numerical models difficult.

Residual stresses are formed during the thermal spraying of coating on a substrate. Residual stresses affect the adhesive strength, cohesive strength, thermal shock resistance, thermal fatigue life, corrosion resistance, wear properties and service life of coatings (Ref 4, 29-35). There are two types of residual stresses-deposition stress (occurring at micro-scale) and post-deposition stress (occurring at macro-scale). Deposition stress is caused due to rapid cooling and solidification of splat, peening action 


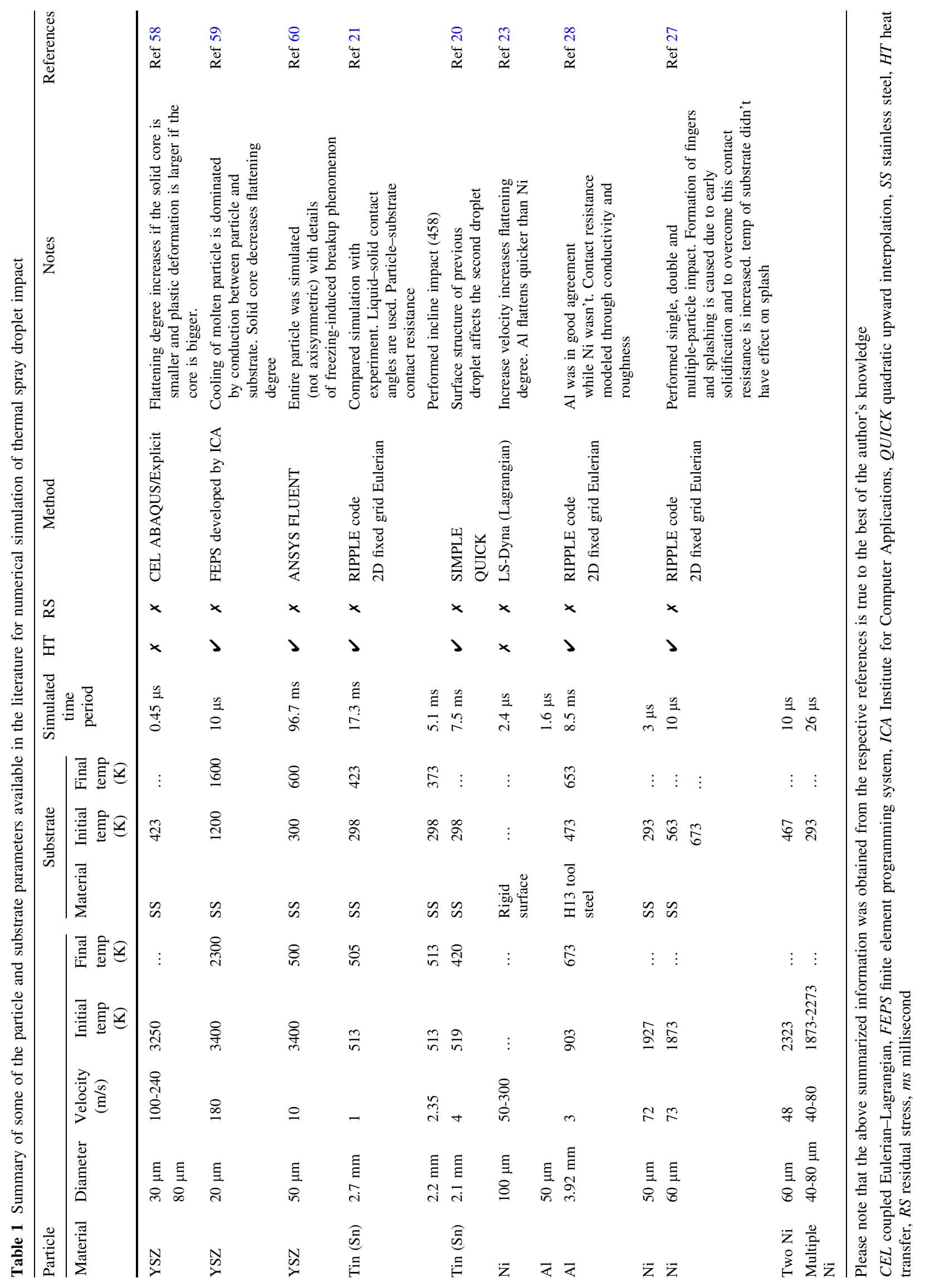


720

Therm Spray Tech (2019) 28:717-736

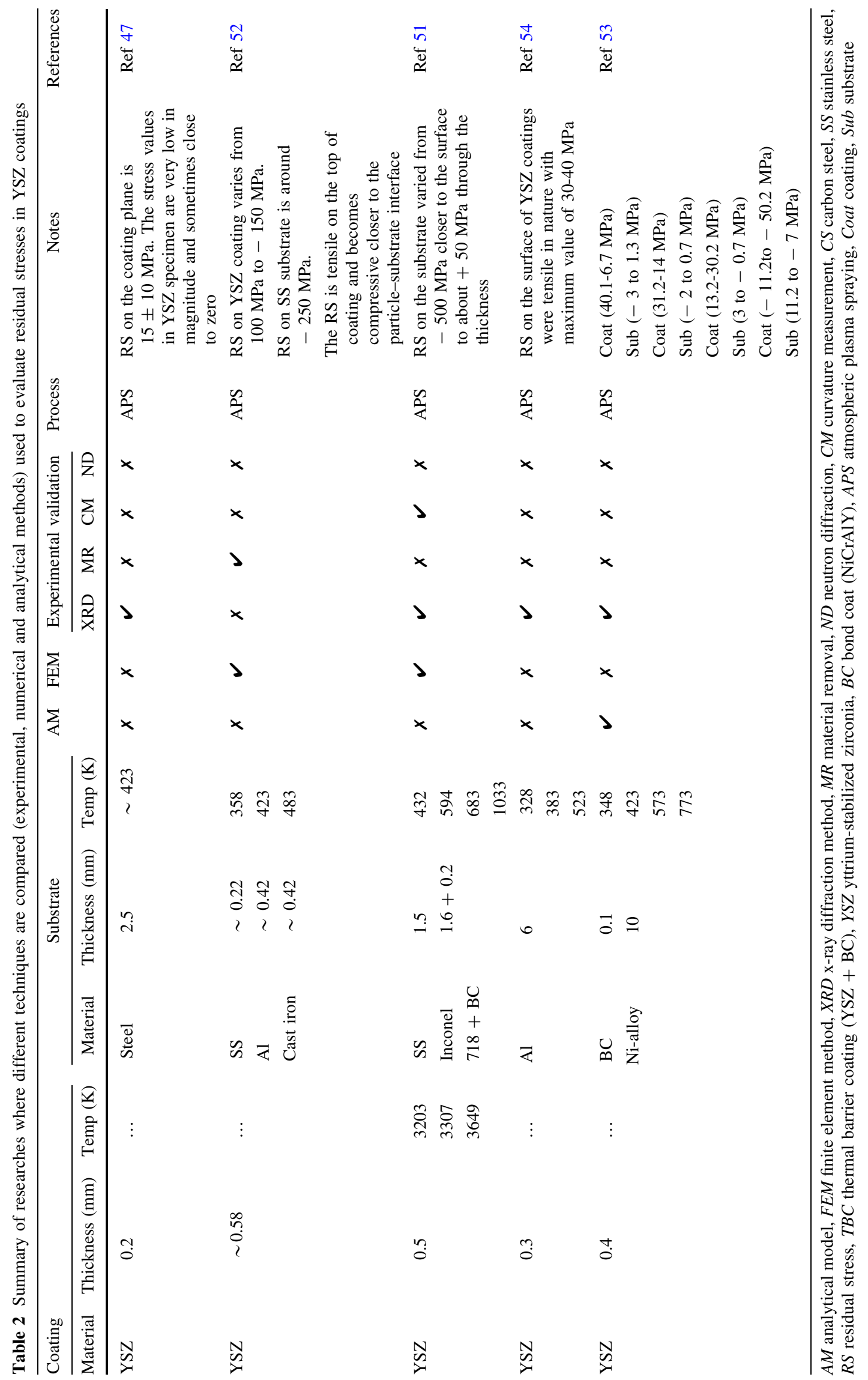

笔 Springer 
(impact) of droplets on a pre-deposited layer or due to high thermal gradients developed (Ref 36). Post-deposition stress is caused by the cooling of the splats to room temperature and due to the mismatch of coefficient of thermal expansion (CTE) of the coating and substrate. Substrate geometry and surface treatment also influence the evolution of residual stresses (Ref 37-39).

Residual stresses are measured experimentally using various methods. Some of the frequently used methods are $\mathrm{X}$-ray diffraction (XRD), in situ curvature measurements, neutron diffraction and incremental hole-drilling methods. $\mathrm{XRD}$ is not able to measure residual stresses in the coating/substrate interface due to the limited penetration of the $\mathrm{X}$-rays (Ref 40). XRD can give inaccurate stress values due to uncertainties in determining elastic parameters (Ref 41, 42). Despite these limitations, XRD has been widely used by many researchers and has been validated with other methods (Ref 43-47). Neutron diffraction utilizes high-energy neutrons which are allowed to penetrate the sample, and the scattering caused by the atoms and nuclei is collected and analyzed (Ref 40). The cost of obtaining sufficient and accurate residual stress data using neutron diffraction is high (Ref 48). In situ curvature measurement is another form of experimental measurement for residual stress. The change in substrate curvature and temperature is used to predict the residual stresses ( $\operatorname{Ref} 49,50)$. It is the only experimental technique that can track deposition and post-deposition stresses separately (Ref 40).

The work presented in Ref 51 by Mutter et al. used in situ curvature measurement to predict residual stresses developed due to the impact of YSZ particle on various substrates while employing the XRD and hole-drilling methods to obtain the residual stress depth profiles in stainless steel. The residual stresses were compressive $(-500 \mathrm{MPa})$ in nature closer to the interface and then had a gradual change to tensile stresses (50 MPa) through the

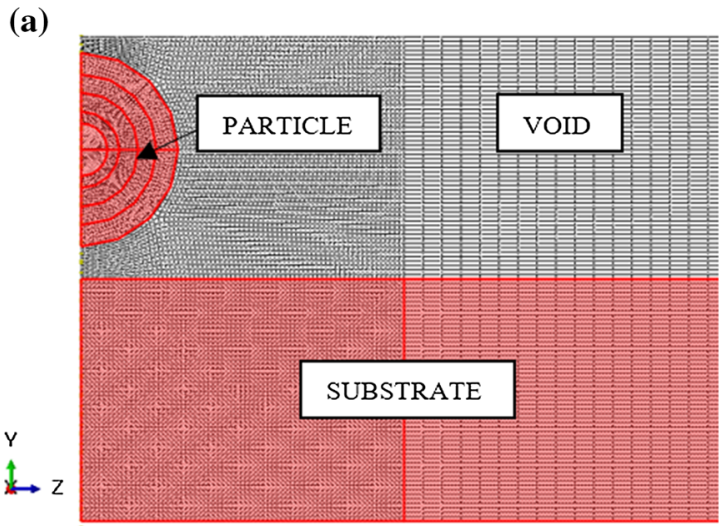

Fig. 1 (a) Computational model of YSZ particle and SS substrate (highlighted in red color) depicting the mesh resolution, (b) Computational model domain with boundary conditions where boundary
Table 3 Details of mesh and elements for validation model (CEL method)

\begin{tabular}{ll}
\hline Solver used & ABAQUS/Explicit \\
Method & CEL \\
Element type-substrate & C3D8R \\
Element type-particle & EC3D8R \\
No. of elements-particle & $1,279,104$ \\
No. of elements-substrate & 247,590 \\
\hline
\end{tabular}

thickness of the SS substrate. Unfortunately, there was no information of residual stress in the YSZ coating. Montay et al. (Ref 52) employed the incremental hole-drilling method to determine the residual stresses developed due to thermal spraying of YSZ on various substrates for different substrate initial temperatures. It was concluded that the change in substrate temperature had little or no influence on the residual stresses for cast iron substrate but had a drastic influence for aluminum and stainless steel substrates. For higher substrate temperatures, the residual stresses in the coating are compressive in nature. For stainless steel substrate at $423 \mathrm{~K}$, the through-thickness residual stress of the coating is tensile closer to the surface (100 MPa) and then follows a very low magnitude of stress $(-10$ to $+10 \mathrm{MPa})$ and then becomes compressive (- $150 \mathrm{MPa})$ closer to the particle-substrate interface. The residual stress on stainless steel is compressive in nature (- $250 \mathrm{MPa})$. Matejicek et al. (Ref 47) used XRD method to analyze residual stresses developed due to deposition of various coating material (YSZ, Mo, NiCrAlY and Ni) of different thicknesses on steel and Al substrates. Notably the in-plane residual stress for the YSZ coating has low stress values (average $15 \pm 10 \mathrm{MPa}$ ) and sometimes close to zero. Possible explanation being that the quenching and thermal mismatch stress having opposite signs and cancel

(b)

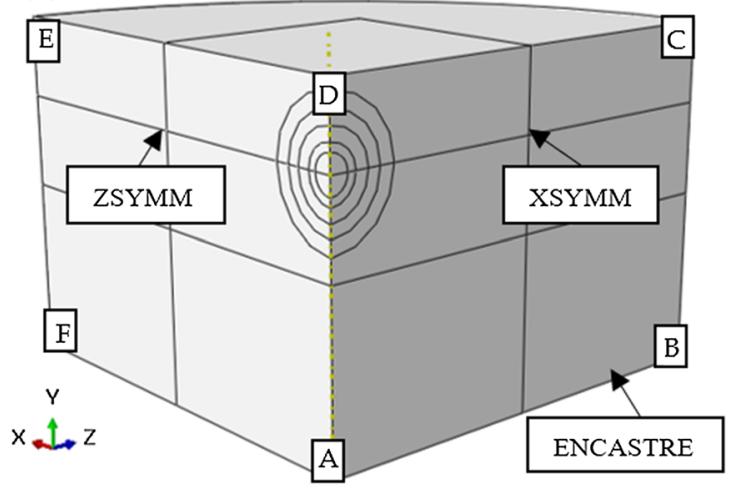

A-B-C-D is given XSYMM boundary condition, boundary A-D-E-F is given ZSYMM boundary condition and bottom surface A-F-B is restricted movement in all directions (Color figure online) 


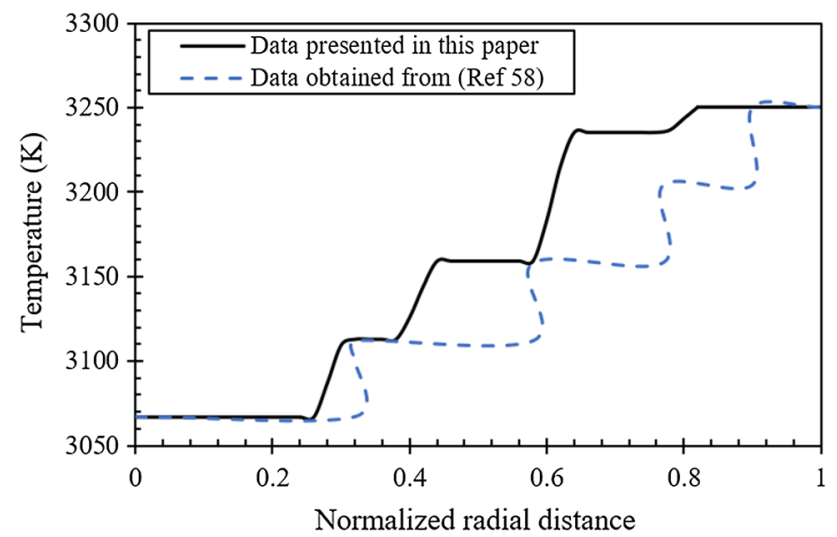

Fig. 2 Comparison of radial temperature distribution of YSZ particle used in this paper with temperature distribution used in the validation paper by Zhu et al. (Ref 58). Normalized radial distance is the distance from the center of the particle up to the particle periphery divided by the particle radius at the respective points

Table 4 Comparison of material properties used for the CEL and Eulerian model

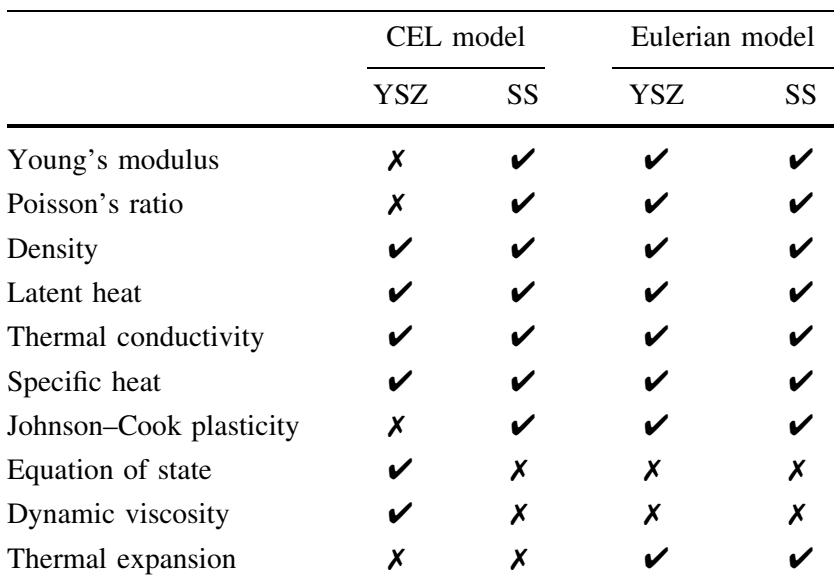

$C E L$ coupled Eulerian-Lagrangian, $Y S Z$ yttrium-stabilized zirconia, $S S$ stainless steel

each other out $(\operatorname{Ref} 53,54)$. Another possible explanation is being stress relaxation due to the formation of micro-cracks (Ref 47). Wang and Xiao (Ref 55) employed Cr 3+ fluorescence spectroscopy to determine residual stresses in $\mathrm{Al}_{2} \mathrm{O}_{3} / \mathrm{YSZ}$ coatings. It was found that the macro-compressive residual stresses were high $(-500$ to $-300 \mathrm{MPa})$ for coating thickness less than $20 \mu \mathrm{m}$. and theoretical model was presented to validate this behavior. Scardi et al. (Ref 54) studied the effect of deposition temperature on the microstructure of YSZ coating on $\mathrm{Al}$ substrate using XRD. It was concluded that the surface of the coating was always in tension (30-40 MPa). Levit et al. (Ref 53) performed residual stress analysis using XRD for YSZ coating on Nibased alloy for various substrate temperatures. It was found that the stresses changed from tensile $(40 \mathrm{MPa})$ to compressive ( $-20 \mathrm{MPa})$ as the temperature was increased and employed mathematical model to verify the results. It was seen that the residual stresses developed in the YSZ coating and $\mathrm{Ni}$ substrate is directly related to the substrate temperature. A problem common to all experimental methods is that they give average stress values which cannot be used to predict the micro-stresses (or localized stresses) that often occur near areas of stress concentration and longer duration is required to optimize spray process experimentally. Hence, numerical simulation (FEM) has been the prime focus to model residual stresses developed in thermal spray coatings (Ref 56).

Most of the numerical models present in the literature to determine residual stresses involve the study of the postdeposition stress, and it is assumed that the splat has completed its flattening process (finite element birth and death method). However, the models presented in the literature suffer from various issues and the results are inaccurate qualitatively and quantitatively. Some of the models that deal with post-deposition residual stresses could be found in Ref 29, 30, 57. The review provided by Clyne et al. (Ref 33) and Abubakar et al. (Ref 40) can be referred for further discussion of development of residual stresses. Table 2 provides details of residual stress for different YSZ coatings on various substrates along with the various techniques used to measure the residual stress with their magnitudes.

This paper builds upon the previous work done by Zhu et al. (Ref 58) for molten YSZ particle impacting a stainless steel substrate. The numerical simulation is performed to validate the model done by Zhu et al. (Ref 58) using coupled Eulerian-Lagrangian method (CEL) in ABAQUS/ Explicit. Due to the limited availability of the numerical models in the literature that provides deposition and postdeposition residual stress analysis, heat transfer model is simulated while including the effect of coefficient of thermal expansion (CTE) using pure Eulerian method in ABAQUS/Explicit.

Table 5 Details of mesh and elements for heat transfer model (Eulerian method)

\begin{tabular}{ll}
\hline Solver used & ABAQUS/Explicit \\
Method & Eulerian \\
Element type-substrate & EC3D8RT \\
Element type-particle & EC3D8RT \\
No. of elements-particle & 440,570 \\
No. of elements-substrate & 402,570 \\
\hline
\end{tabular}




\section{Numerical Method}

\section{Validation Model: CEL Method}

A fully molten YSZ (yttrium-stabilized zirconia) particle of $30 \mu \mathrm{m}$ diameter impacting stainless steel (SS) substrate (circular disk of radius $100 \mu \mathrm{m}$ and height of $37.5 \mu \mathrm{m}$ ) for impact velocities of 100, 150, 190 and $240 \mathrm{~m} / \mathrm{s}$ is modeled using coupled Eulerian-Lagrangian method (CEL) in ABAQUS/Explicit. Owing to the axisymmetric nature of the normal impact, a quarter of the 3D model was simulated. Since CEL is based on volume of fluid (VOF) approach (Ref 59), there is a presence of void material shown in Fig. 1(a). The boundary conditions used in the numerical model are shown in Fig. 1(b). The bottom of the domain (boundary surface A-F-B) was restricted movement in all directions, while the symmetrical boundary condition in Z-direction and $\mathrm{X}$-direction was applied to the boundary surfaces A-D-E-F and A-B-C-D, respectively. The Eulerian and Lagrangian elements were assigned to the particle and substrate, respectively. Further details of the element types could be found in Table 3 .

For the interaction, "General contact, All-with-self" was defined for the model. And the particle velocity and temperatures were defined using the "Pre-defined field." The substrate was preheated to $423 \mathrm{~K}$. Due to the relatively low thermal conductivity of the YSZ material, a temperature gradient occurs in the YSZ particle, hence different temperatures were assigned to various sections of the YSZ particle ranging from 3067 to $3250 \mathrm{~K}$. The radial temperature distribution given in the model presented within this paper is shown in Fig. 2 and is compared with temperature distribution used in the model by Zhu et al. (Ref 58). The material parameters used in the CEL model for YSZ and SS are displayed in Table 4. The model was simulated using dynamic/explicit step with a total step time of $0.7 \mu \mathrm{s}$ which was enough for the kinetic energy of the particle to become closer to zero and complete its flattening process. The simulation took around 6-7 days on Lenovo ${ }^{\circledR}$ ThinkCentre workstation with 6 parallel processors.

\section{Heat Transfer Model: Eulerian Method}

The heat transfer model was simulated using pure Eulerian method for a single YSZ particle (diameter of $30 \mu \mathrm{m}$ ) impacting SS substrate (circular disk of radius $100 \mu \mathrm{m}$ and height of $37.5 \mu \mathrm{m}$ ). The particle and substrate parameters are same as the validation model ("Validation Model: CEL Method" section). The heat transfer model includes the solidification and the residual stresses developed during and post-deposition of the particle. The effect of coefficient of thermal expansion (CTE) was included to study the macro-residual stresses. The following are the assumptions considered in the heat transfer model:

1. Surface roughness of the substrate is not considered

2. The particle is assumed to be fully molten

3. Phase transformation is not considered

4. Phase change from liquid to solid is considered

5. The oxidation and impurities in the coating is ignored

6. The intermediate cooling between the layer is ignored

7. Perfect bonding between the coating and substrate is considered

8. Heat transfer between the coating and substrate is only through conduction

9. The formation of macro- and micro-cracks in the coating is ignored

Temperature-dependent elastic parameters were used in heat transfer model, due to incompatibility of including equation of state (EOS) and coefficient of thermal expansion (CTE) for the same material within ABAQUS (Ref 59). The material parameters used in Eulerian model for YSZ and SS are displayed in Table 4. The interactions were not defined for the model, since ABAQUS ${ }^{\circledR}$ defines default contact for Eulerian analysis which is a limitation since thermal contact resistance (inverse of thermal conductance) cannot be defined between the particle and substrate. However, as stated by Xue et al. (Ref 28) the thermal contact resistance can be modified by changing the thermal conductivity. Hence, the thermal conductivities of the SS and YSZ materials were manipulated to vary the contact resistance. To observe the solidification and cooling of the molten YSZ, the model was simulated using the dynamic explicit temperature-displacement step. For further details of the elements, refer to Table 5. To reduce the computational time, the mesh domain was made smaller and the mesh was refined in the impact region. The simulation took around 2-3 days on Lenovo ${ }^{\circledR}$ ThinkCentre workstation with 6 parallel processors.

\section{Multiple Impact Model Without Substrate Cooling}

A multiple impact model has been simulated with a total number of 100 YSZ particles (diameter of $80 \mu \mathrm{m}$ ) impacting SS substrate (circular disk of radius $100 \mu \mathrm{m}$ and height of $37.5 \mu \mathrm{m}$ ) with an impact velocity of $240 \mathrm{~m} / \mathrm{s}$ for Case A. In reality, the particles impact in a random manner to form layers but to reduce computational time the particles were modeled to impact in the same location and axisymmetric model has been simulated. The particles have been preheated to a temperature of $3000 \mathrm{~K}$ and the substrate was preheated to $423 \mathrm{~K}$. The material properties of the YSZ and SS used in the multiple impact model are the same as describer earlier in "Heat Transfer Model: Eulerian Method" section. The model considers heat 
transfer using Eulerian thermally coupled brick element (EC3D8RT) and uses dynamic explicit temperature-displacement step for a total time step of $140 \mu$ s. The simulation took around 15 days on Lenovo ${ }^{\circledR}$ ThinkCentre workstation with 6 parallel processors.

\section{Multiple Impact Model with Substrate Cooling}

A multiple impact model has been simulated with a total number of 100 YSZ particles (diameter of $80 \mu \mathrm{m}$ ) impacting SS substrate (circular disk of radius $100 \mu \mathrm{m}$ and height of $37.5 \mu \mathrm{m}$ ) with an impact velocity of $100 \mathrm{~m} / \mathrm{s}$ for Case A. An axisymmetric model has been simulated to reduce computational time and the particles impact in the same location. The particles have been preheated to a temperature of $3000 \mathrm{~K}$, and the top surface of the substrate was preheated to $423 \mathrm{~K}$ while the rest of the substrate was heated to $298 \mathrm{~K}$ to mimic the cooling effects generated in the experimental setup. The lower temperature of $298 \mathrm{~K}$ was given as a boundary condition to the outer surface, and this region maintains the same temperature throughout the simulation to mimic air cooling of substrate during spraying. While, the substrate temperature of $423 \mathrm{~K}$ was given as a pre-defined field and the temperature in this region can change during the simulation. A smooth temperature gradient in the substrate would be more realistic but due to the lack of experimental data, a sharp temperature gradient was used in the model. The material properties of the YSZ and
SS used in the multiple impact model are same as in "Heat Transfer Model: Eulerian Method" section. The model considers heat transfer using Eulerian thermally coupled brick element (EC3D8RT) and uses dynamic explicit temperature-displacement step for a total time step of $100 \mu$ s. The simulation took around 20 days on Lenovo ${ }^{\circledR}$ ThinkCentre workstation with 6 parallel processors.

\section{Computational Parameters}

\section{Mie-Gruneisen Equation of State}

Equation of state (EOS) is a thermodynamic equation describing the state of solid, fluids and even mixtures of fluids. Mie-Gruneisen EOS is widely used for solid materials (Ref 60) and it provides the relation between pressure and volume at a given state of pressure and temperature. Gustav Mie (1903) developed a model to measure the intermolecular potential for equation of state of high temperature solids (Ref 61). In 1912, Gruneisen extended Mie's model (Ref 62) and his form of equations have been the starting point for derivation of Mie-Gruneisen EOS. The thermodynamic behavior, such as pressure and internal energy of real material can be categorized by the following two-term relations (Ref 63):

$e(V, T)=e_{\text {ref }}(V)+e_{T}(V, T)$

(Eq 1)
Table 6 Material properties used in the numerical model for yttrium-stabilized zirconia (YSZ) and stainless steel (SS)

\begin{tabular}{llll}
\hline & \multicolumn{2}{c}{ YSZ } & SS \\
\hline Thermal conductivity (solid) & 2.32 & 14.9 & $\mathrm{~W} / \mathrm{mK}$ \\
Thermal conductivity (liquid) & 2 & 33 & $\mathrm{~W} / \mathrm{mK}$ \\
Latent heat & 706,800 & 272,000 & $\mathrm{~J} / \mathrm{kg}$ \\
Solidus temperature & 2799 & 1710 & $\mathrm{~K}$ \\
Liquidus temperature & 2801 & 1774 & $\mathrm{~K}$ \\
Density & 5890 & 7900 & $\mathrm{~kg} / \mathrm{m}^{3}$ \\
Specific heat capacity (solid) & 580 & 477 & $\mathrm{~J} /(\mathrm{kg} \mathrm{K})$ \\
Specific heat capacity (liquid) & 713 & 627 & $\mathrm{~J} /(\mathrm{kg} \mathrm{K})$ \\
Young's modulus & 241 & 200 & $\mathrm{GPa}$ \\
Poisson's ratio & 0.32 & 0.3 & - \\
Coefficient of thermal expansion $(C T E)$ & $6.3 \times 10^{-6}$ & $1.54 \times 10^{-5}$ & $\mathrm{~K}$ \\
Johnson-Cook fitting parameter $(A)$ & 420 & 310 & $\mathrm{MPa}$ \\
Johnson-Cook fitting parameter $(B)$ & 521 & 1000 & $\mathrm{MPa}$ \\
Johnson-Cook fitting parameter $(C)$ & 0.07 & 0.07 & $\ldots$ \\
Johnson-Cook fitting parameter $(n)$ & 0.184 & 0.65 & $\ldots$ \\
Johnson-Cook fitting parameter $(m)$ & 0.0197 & 1 & $\ldots$ \\
Johnson-Cook fitting parameter $\left(\varepsilon_{\mathrm{o}}\right)$ & 0.418 & 0.418 & $\ldots$ \\
Melting temperature & 2988 & 1673 & $\mathrm{~K}$ \\
Transition temperature & 298 & 298 & $\mathrm{~K} / \mathrm{s}$ \\
Speed of sound (liquid) & 3000 & $\ldots$ & \\
EOS parameter $(s)$ & 2.39 & & $\mathrm{~K}$ \\
\hline & & $\ldots$ &
\end{tabular}




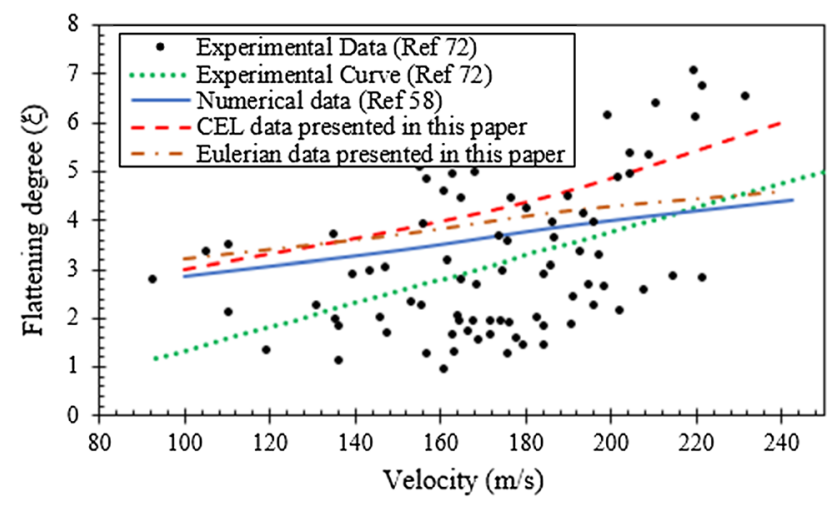

Fig. 3 Variation of flattening degree with particle impact velocity for experimental data by Vardelle et al. (Ref 72), validation data from numerical simulation by Zhu et al. (Ref 58) with the CEL and Eulerian data obtained in this paper

$p(V, T)=p_{\text {ref }}+\frac{\Gamma(V)}{V} e_{T}(V, T)$

where $V=1 / \rho$ denotes the specific volume, $T$ denotes the temperature, $p$ is the pressure, $e$ is the internal energy and $\Gamma$ is the Gruneisen parameter which represents the thermal pressure from a set of vibrating atoms (Ref 58). The subscript ref represents the parameters at the reference state. Combining the above two equations of internal energy and pressure, the Mie-Gruneisen EOS (Ref 64) is obtained:

$p-p_{H}=\frac{\Gamma}{V}\left(E_{m}-E_{H}\right)$

where $p_{H}$ and $E_{H}$ are pressure and internal energy along the Hugoniot as functions of only volume, the Mie-Gruneisen parameter $\Gamma$ is defined as:

$\Gamma=\Gamma_{o} \frac{\rho_{o}}{\rho}$

where $\Gamma_{o}$ is material constant and $\rho_{o}$ is reference density. $E_{H}$, Hugoniot energy is given by:
$E_{H}=\frac{p_{H} \eta}{2 \rho_{o}}$

where $\eta=1-\left(\rho / \rho_{o}\right)$ is the nominal volumetric compressive strain.

$p=p_{H}\left(1-\frac{\Gamma_{o} \eta}{2}\right)+\Gamma_{o} \rho_{o} E_{m}$

\section{Linear $U_{s}-U_{p}$ Hugoniot Form}

Mie-Gruneisen EOS is represented in linear $U_{\mathrm{s}}-U_{p}$ form using the Rankine-Hugoniot approximation for purposes of computational mechanics (Ref 65). The EOS in the absence of dynamic yielding effects or phase transitions, along with linear fit assumption for shock velocity as function of particle velocity (Ref 58) is given by Ref 66:

$U_{s}=C_{o}+s U_{p}$

where $U_{s}$ represents the shock velocity, $C_{o}$ is the isentropic speed of sound, $U_{p}$ is the velocity of the particle, $s$ is a dimensionless parameter which is related to the pressure derivative of the isentropic bulk modulus (Ref 58). The final form of the $U_{\mathrm{s}}-U_{p}$ equation is given by:

$p=\frac{\rho_{o} C_{o}^{2}}{(1-s \eta)^{2}}\left(1-\frac{\Gamma_{o}}{2}\right)+\Gamma_{o} \rho_{o} E_{m}$

The speed of sound in YSZ is taken as $3000 \mathrm{~m} / \mathrm{s}$ and the dimensionless parameter $s$ is taken as 2.39 (Ref 67, 68).

\section{Johnson-Cook Plasticity Model}

When materials are subjected to dynamic loading conditions (such as high velocity impact), a wide range of strain, strain rate, pressure and temperature are experienced (Ref 69). The Johnson-Cook plasticity model (Ref 69, 70) provides the elastic-plastic response of the stainless steel and yttrium-stabilized zirconia (YSZ). Johnson-Cook
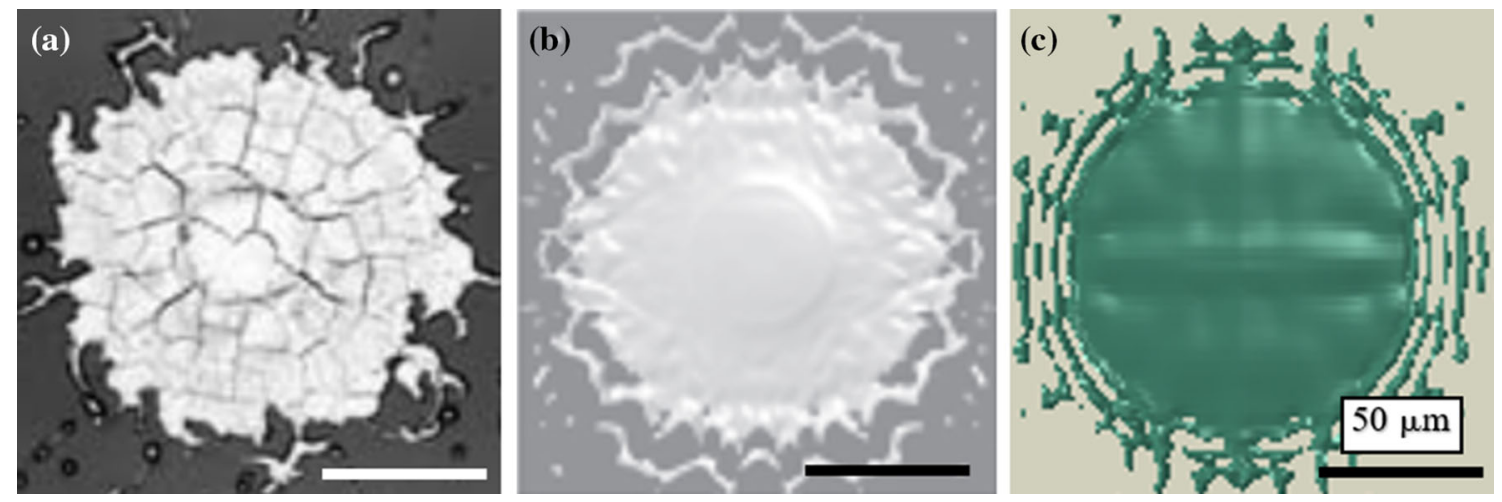

Fig. 4 Comparison of final splat morphology for YSZ coating on SS substrate, (a) experimental data by Shinoda and Murakimi (Ref 74), (b) numerical data by Zhu et al. (Ref 58), (c) CEL data obtained in the current study (bar indicates $50 \mu \mathrm{m}$ ) 
Table 7 Multiplication factor used for thermal conductivities for YSZ and SS in ABAQUS ${ }^{\circledR}$

\begin{tabular}{lrr}
\hline & YSZ & SS \\
\hline Case A & 10 & 10 \\
Case B & 1 & 10 \\
\hline
\end{tabular}

model provides material properties that are subject to high strain rates and high temperature $(\operatorname{Ref} 70)$ :

$\sigma=\left(A+B \varepsilon^{n}\right)\left(1+C \ln \dot{\varepsilon}^{*}\right)\left(1-T^{* m}\right)$

where $\varepsilon$ is equivalent plastic strain, $\dot{\varepsilon}^{*}=\dot{\varepsilon} / \dot{\varepsilon}_{o}$ is the dimensionless plastic strain rate and $T^{*}$ is homologous temperature. The five material constants are $A, B, n, C$ and $m$ are static yield strength, strain-hardening exponent, strain-hardening modulus, strain-rate-sensitive coefficient and thermal-softening exponent. The Johnson-Cook parameters for stainless steel (SS) and yttrium-stabilized zirconia (YSZ) are defined in Table 6 along with other material properties.

\section{Temperature-Dependent Viscosity}

Due to the low thermal conductivity, ceramic powder develops temperature gradient (Ref 71, 72). There is large temperature difference between the particle and substrate. Since Mie-Gruneisen EOS is defined for the YSZ particle, a temperature-dependent viscosity must be defined for accurate results. Temperature-dependent viscosity is found in the work done by Vardelle et al. (Ref 72) which is validated by Shinoda et al. (Ref 73):

$\mu[\mathrm{Pa} \mathrm{s}]=0.1 \exp \left[-2.95+\frac{5993}{T}\right]$
Fig. 5 Calculated temperature distribution (Kelvin) of YSZ particle of $30 \mu \mathrm{m}$ diameter with a particle temperature of 3250-3067 $\mathrm{K}$ and particle impact velocity of $240 \mathrm{~m} / \mathrm{s}$ impacting stainless steel (SS) substrate with a substrate temperature of $423 \mathrm{~K}$ for (a) Case A and (b) Case B. Temperatures above the melting point $(2988 \mathrm{~K})$ are in gray color (Color figure online) (a)

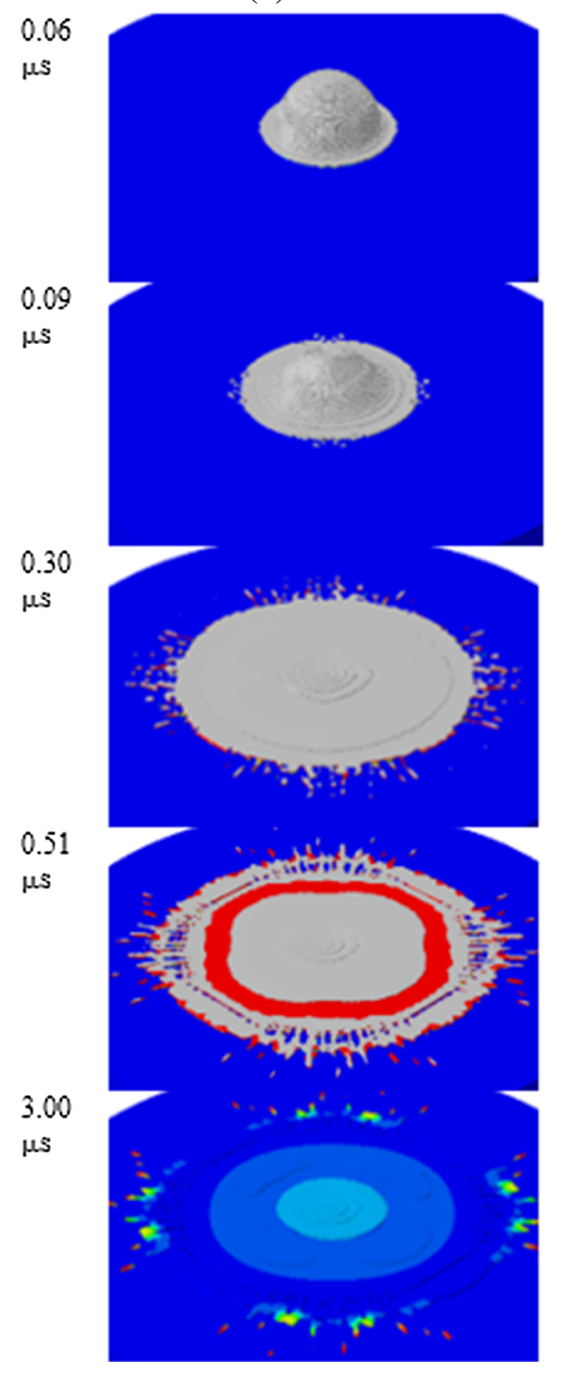

(b)

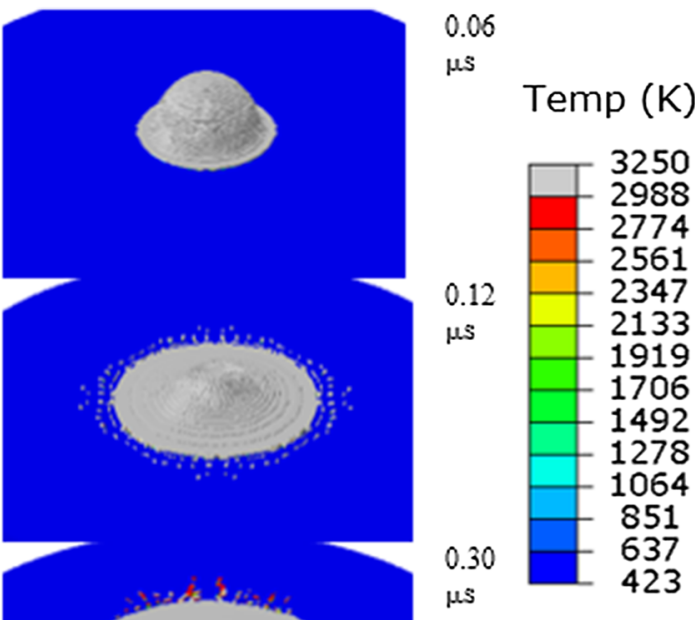




\section{Results and Discussion}

\section{Validation Model}

Molten zirconia (YSZ) of particle diameter $30 \mu \mathrm{m}$ impacting stainless steel substrate which was preheated to $423 \mathrm{~K}$ was simulated using ABAQUS ${ }^{\circledR} 6.16$ for particle impact velocity ranging from 100 to $240 \mathrm{~m} / \mathrm{s}$, to validate the model. Due to the low thermal conductivity of zirconia, the particle develops thermal gradient along the radius of the sphere (Ref 58, 71). The quantitative validation was based on variation of flattening degree for different impact velocities. Flattening degree $(\zeta)$ is the ratio of the diameter of final splat and the particle diameter prior to the impact. The obtained results were compared with experimental data (Ref 72) and numerical simulation by Zhu et al. (Ref 58) on the basis of flattening degree. Figure 3 depicts the comparison of the experimental and validation data with the data obtained within this paper. The numerical data from the literature exhibit linear behavior showing that the flattening degree increases with the increase in impact velocity (Ref 58) while the experimental data obtained are highly scattered. For an impact velocity, the flattening degree varies from 1 to 5 , showing the highly unpredictable nature of experimental results. The flattening degree obtained from the CEL and Eulerian model in this paper is found to be in close agreement with the experimental and numerical data. However, the flattening degree obtained from CEL has higher flattening degree at higher velocities, the data obtained from Eulerian model's prediction of flattening degree are in better agreement with numerical data obtained by Zhu et al. (Ref 58). The final splat shape obtained was compared with the experimental data by Shinoda and Murakimi (Ref 74) and numerical data by Zhu et al. (Ref 58) which are in good agreement (Fig. 4). The final splat shapes have a thick central splat with an uneven formation of fingers in the periphery due to rapid heat transfer. The formation of micro-cracks is observed in ceramic materials which are formed due to residual stress relaxation and the formation of macrocracks is due to the relaxation of expansion mismatch stress (Ref 1). The formation of cracks is seen in the experimental splat (Fig. 4a) which are micro-cracks in the center which is caused due to the stress relaxation. The modeling of thermo-mechanical simulation along with the fracture mechanics phenomenon brings along many complications and most of the commercially available softwares are not able to perform simulation of this complexity. Hence, the numerical model simulated in this paper considers only the thermo-mechanical simulation.

\section{Heat Transfer Model}

The heat transfer model of YSZ impacting SS with impact velocity of $240 \mathrm{~m} / \mathrm{s}$ was simulated using Eulerian method in ABAQUS/Explicit. The cooling of the splat is governed by three modes of heat transfer, namely conduction (to the substrate), convection and radiation (to the surrounding gas). The heat transfer model presented in this paper considers conduction as the only mode of heat transfer as it is dominant over convection and radiation. The heat transfer from the droplet to the surrounding gas is ignored as the heat transfer magnitude is three orders lower than heat transfer to the substrate (Ref 27). Due to the unavailability of interaction properties in Eulerian method in ABAQUS, thermal gap conductance couldn't be provided to the model. From the experimental study by Vardelle et al., the cooling rates for zirconia $\left(8 \mathrm{wt} . \% \mathrm{Y}_{2} \mathrm{O}_{3}\right.$ ) coating on smooth steel substrate were estimated to be approximately $100-400 \mathrm{~K} / \mu \mathrm{s}$ (Ref 72). Hence, the original thermal conductivities were varied to match the cooling rates obtained by Vardelle et al. (Ref 72). The assumption by Xue et al. (Ref 28) that the thermal contact resistance (inverse of thermal conductance) can be varied using surface roughness and thermal conductivity is used in the favor to justify the manipulation of the thermal conductivity in this model. Table 7 shows the two cases, Case A and Case B, for which simulations were performed.

\section{Droplet Impact, Spreading and Solidification}

The evolution of the splat morphology of YSZ impacting at $240 \mathrm{~m} / \mathrm{s}$ on SS substrate for Case A and Case B is depicted in Fig. 5. The various time intervals from the instant of the impact up to complete spreading are represented next to the respective images. When a droplet impacts a surface, it would do one of the two main processes, "the particle may impinge, spread and then solidify or it may deform, impinge and then splash." The splashing is experienced due to either low heat transfer which leads to fragmentation or due to freezing-induced breakup due to very rapid heat transfer as indicated in (Ref 75). Case A (Fig. 5a) has a more pronounced effect of freezing-induced break up since both YSZ and SS conductivity were multiplied by 10 which leads to very rapid heat transfer. As the droplet is spreading radially outwards, if it has enough momentum it jets over the solidified layer leading the splat to reach an unstable point and breaks into smaller fragments. In both the cases, it is seen that the droplet has completed the spreading mechanism approximately at $0.5 \mu \mathrm{s}$ and following that the substrate absorbs the heat which leads to the cooling of the splat.

For Case B (Fig. 5b), it is noticed that it experiences less freezing-induced breakup phenomenon when compared 

acting in the $\mathrm{XZ}$ plane for substrate initial temperature of $423 \mathrm{~K}$ with YSZ particle impacting at $240 \mathrm{~m} / \mathrm{s}$ with the initial temperature of the particle from 3250 to $3067 \mathrm{~K}$ for Case A (a) Residual stresses on the YSZ particle (sectional isometric view), (b) residual stresses on the SS substrate (front view). Tensile stresses are represented in color spectrum and compressive stresses are represented in gray/black color (Color figure online)
Fig. 6 Residual stresses (MPa)

(a)

(b)

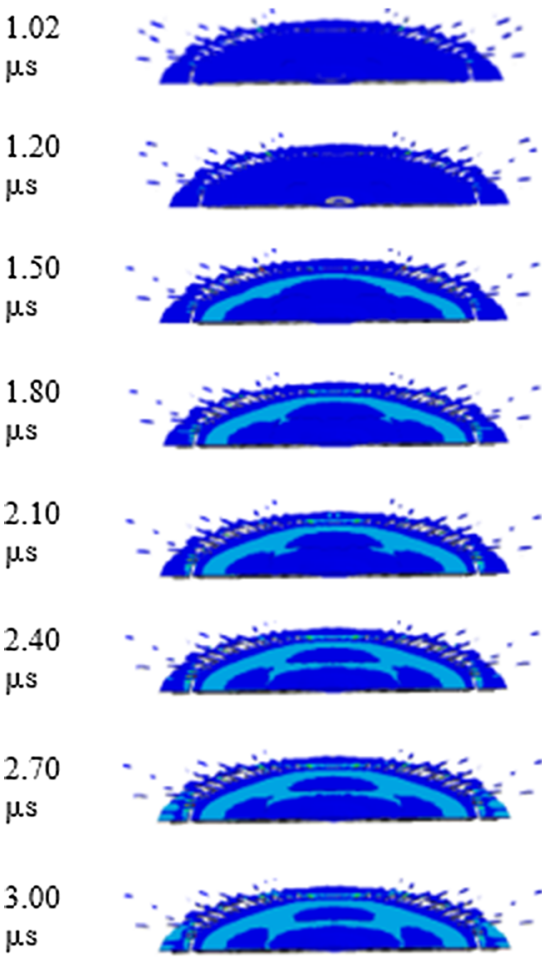

(a)

acting in the $\mathrm{XZ}$ plane for substrate initial temperature of $423 \mathrm{~K}$ with YSZ particle impacting at $240 \mathrm{~m} / \mathrm{s}$ with the initial temperature of the particle from 3250 to $3067 \mathrm{~K}$ for Case B (a) residual stresses on the YSZ particle (sectional isometric view), (b) residual stresses on the SS substrate (front view). Tensile stresses are represented in color spectrum and compressive stresses are represented in gray/black color (Color figure online)

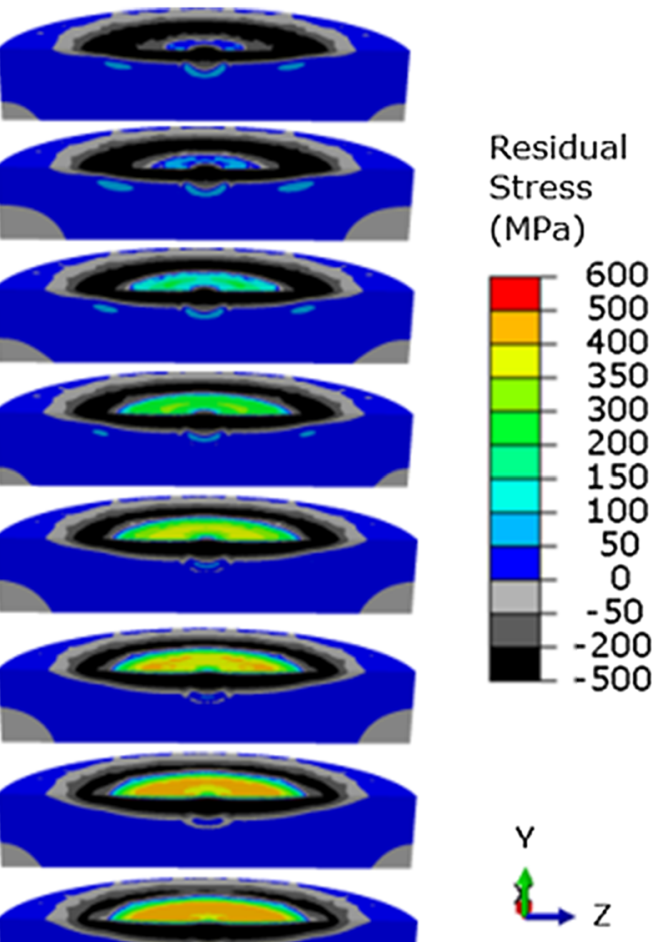

(b)

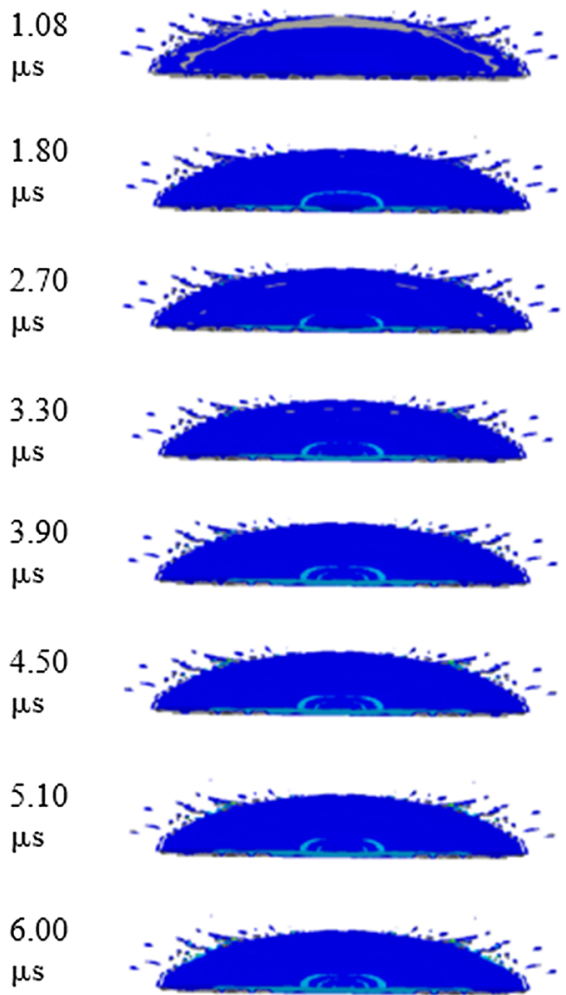

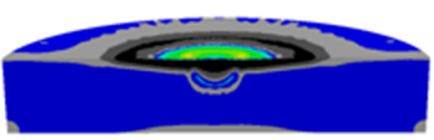
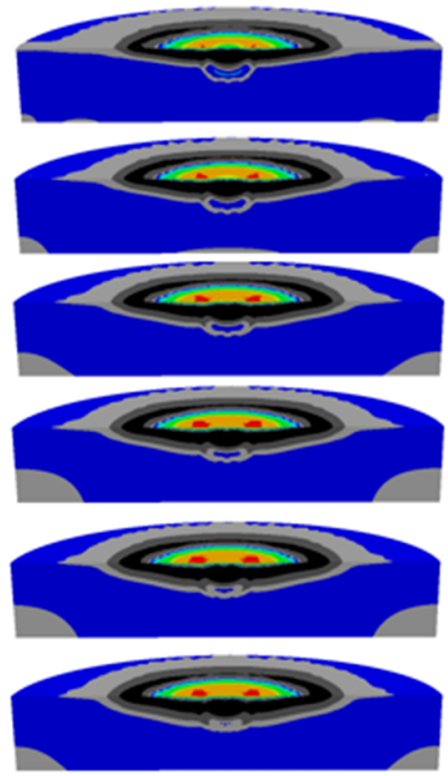

Y

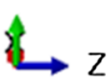


with Case A. This is due to the comparatively slower rate of heat transfer between the splat and the substrate since only the conductivity of YSZ was multiplied with a factor of 10 , while the conductivity of SS material was left at the original conductivity values which makes the thermal conductance value lower. At time instant of $0.12 \mu \mathrm{s}$, as soon as the droplet impacts the substrate, there are formations of very tiny satellite droplets. This is also due to sudden heat transfer, which causes the momentum of the molten droplet to overcome the solidified layer and reach an unstable condition leading to the formation of these droplets. Comparing the cooling rates of Case A and Case $\mathrm{B}$, it is seen that the splat cools down relatively faster for Case A and most of the splat has obtained a uniform temperature value ranging from 423 to $635 \mathrm{~K}$ with the exceptions of some fragments in the outer region that are at a relatively higher temperature. Whereas for Case B, it is seen that the outer region of the splat is still at higher temperature range of $2800 \mathrm{~K}$ at the end of time instant of $6 \mu \mathrm{s}$. This shows the slower rate of cooling for Case B even though it was run at twice the time step of Case A, showing that the splat requires extra time to completely cool down.

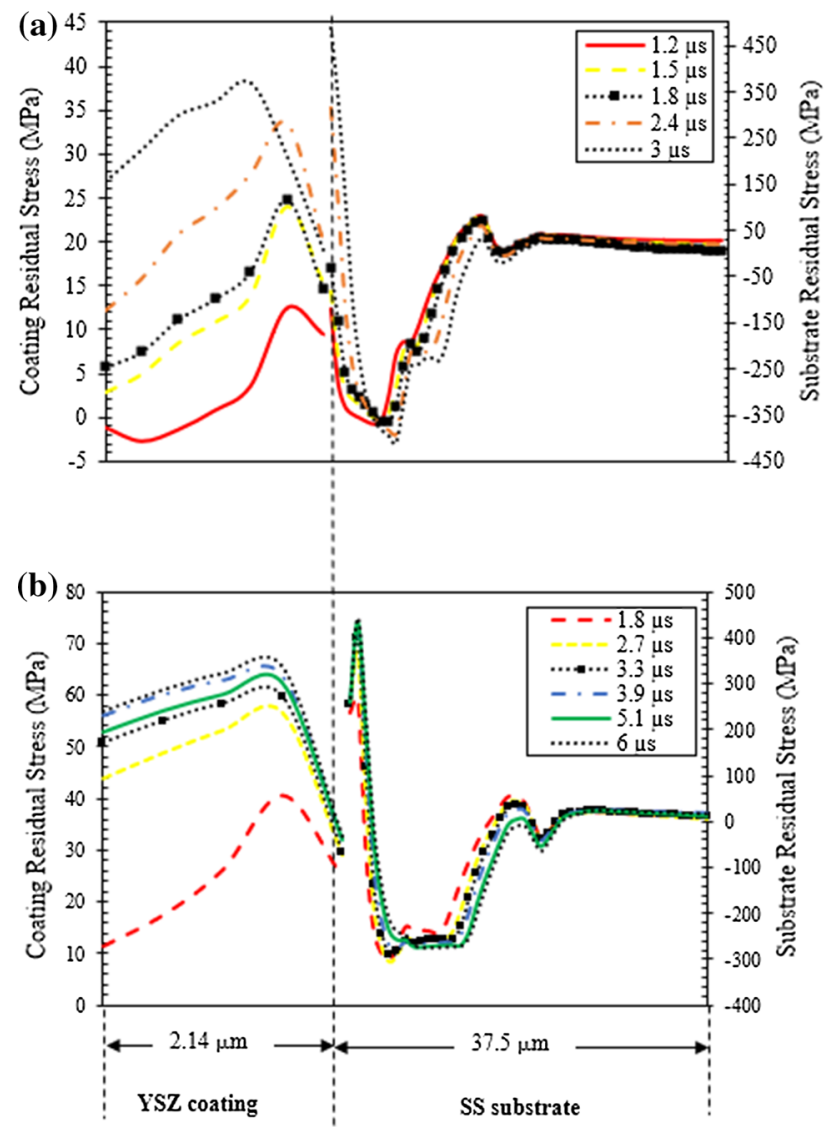

Fig. 8 Through-thickness residual stress distribution for YSZ coating and SS substrate at different time instants for YSZ particle with impact velocity of $240 \mathrm{~m} / \mathrm{s}$ in the XZ plane (in-plane stresses), (a) Case A and (b) Case B
There have been experimental claims that the splat morphology is affected by the substrate temperature and that above a critical temperature known as transition temperature (TT) (Ref 1) the obtained splats are less prone to splashing. The experimental observations by Shinoda and Murakami (Ref 74) of YSZ droplets impacting quartz glass at various substrate temperatures predicted that the transition temperature was between 513 and $673 \mathrm{~K}$. However, the transition temperature varies for each substrate material. The numerical simulation done by Xue et al. (Ref 28) for metallic droplets impacting substrates using variable thermal contact resistance concluded that for a particular thermal contact resistance, increasing the substrate temperature did not reduce the splashing experienced by the splat. There have been experimental reports that increasing the temperature of the substrate increases the thermal contact resistance by the formation of oxide layer which is the main reason due to which droplets experience lesser degree of splashing (Ref 76). Hence, increasing substrate temperature in numerical models does not affect the results as oxide layer formation is ignored and thermal contact resistance is varied.

\section{Evolution of Residual Stress for Single Particle}

The evolution of residual stresses for the YSZ coating on SS substrate for impact velocity of $240 \mathrm{~m} / \mathrm{s}$ for Case A is depicted in Fig. 6. The in-plane stresses acting on the XZ plane are plotted and the values of the stresses in the legend are in MPa. The contours are plotted for the YSZ coating post-spreading. In thermal spray literature, the stresses developed due to the plastic deformation of the particle on the substrate or on previously deposited layer are known as peening stress (Ref 1$)$. Due to the nature of the reaction forces induced due to the impact, peening stresses are usually compressive in nature ( $\operatorname{Ref} 40)$. At the time instants of 1.02 and $1.20 \mu$ s for Fig. 6(a), the bulk of the YSZ particle experiences tensile stresses (up to $50 \mathrm{MPa}$ ) on the top surface with very minor regions in the lower surface having compressive stresses $(-50$ to $-200 \mathrm{MPa}$ ), while the substrate at these time instants develop large magnitudes of compressive residual stress $(-200$ to $-500 \mathrm{MPa}$ ) around the region of impact. The periphery and the center of the substrate experiences very low levels of tensile stresses (up to $50 \mathrm{MPa}$ ). At time instant of $1.5 \mu \mathrm{s}$, the tensile stresses in the YSZ coating increases slightly and is within the range of 50-100 MPa with the lower region developing high compressive stresses $(-200$ to $-500 \mathrm{MPa}$ ). The region of tensile stresses acting in the center of the substrate expands radially and is within the range of $100-150 \mathrm{MPa}$. After $1.5 \mu \mathrm{s}$, there is an overall effect of tensile stresses observed in the particle and a combination of tensile and compressive stress in the 
substrate, which is caused due to the quenching stress. Quenching stresses are developed due to the sudden solidification of flattened molten particles from melting point to room temperature (Ref 1,40$)$. The sudden solidification and shrinkage occurring at the micro-scale within the splat causes the formation of tensile stresses due to thermal mismatch stress and constrained shrinkage of the splat due to interfacial bonding (Ref 1). The thermal gradients developed through the thickness for thick coatings at macro-scale cause the substrate to bend and distort (dependent on the degree of thermal mismatch). The thermal gradient is more harmful for ceramic coatings (such as YSZ) due to the low thermal conductivity (Ref 1).

For time instants of 1.8-3 $\mu$ s, post-deposition mismatch stresses are dominant over the peening and quenching stresses. Occurring at a macro-scale, post-deposition mismatch stress is primarily caused due to the difference in the properties (CTE, coefficient of thermal expansion) of the coating and substrate material (Ref 40). Post-deposition mismatch stresses are often known to have highest magnitudes and affect the overall residual stresses significantly. For ceramic coatings, the post-deposition mismatch stress is usually overall compressive in nature, which is the outcome of the substrate residual stresses from $0.48 \mu \mathrm{s}$ onwards. The stresses are compressive due to the lower CTE of the YSZ when compared with SS.

The evolution of residual stresses for the YSZ coating on SS substrate for impact velocity of $240 \mathrm{~m} / \mathrm{s}$ for Case B is depicted in Fig. 7. The in-plane stresses acting on the XZ plane is plotted, and the values of the stresses in the legend are in MPa. The contours are plotted for the YSZ coating post-spreading. At the time instant of $1.08 \mu \mathrm{s}$, majority of the coating surface is tensile (up to $50 \mathrm{MPa}$ ) with a minor ring-like region of compressive stresses (up to - $50 \mathrm{MPa}$ ). The lower surface of the YSZ coating has some regions

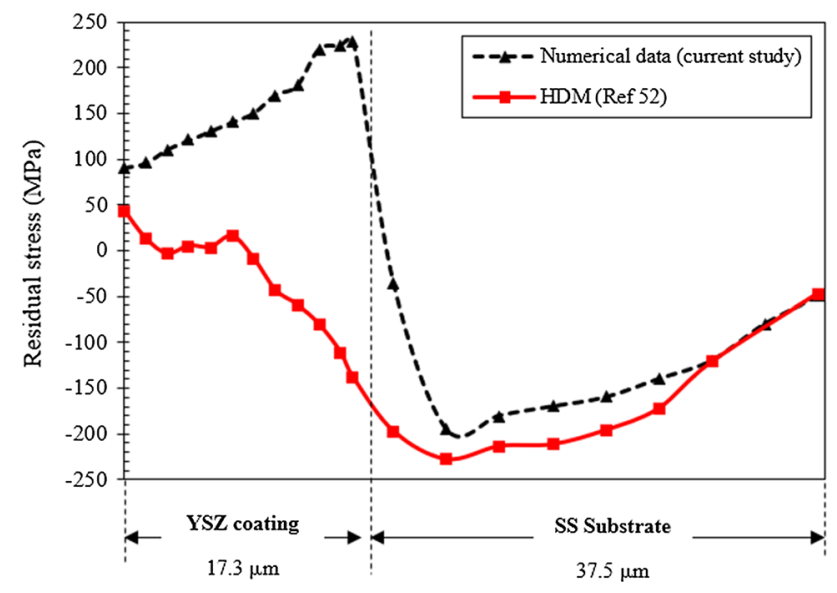

Fig. 10 Comparison of through-thickness residual stress distribution for YSZ coating (thickness $17.3 \mu \mathrm{m})$ on SS substrate $(37.5 \mu \mathrm{m})$ without substrate cooling obtained from the current study for impact velocity of $240 \mathrm{~m} / \mathrm{s}$ with the stress profile obtained by hole-drilling method by Montay et al. (Ref 52). Note: The coating thickness of YSZ coating by Montay et al. was $590 \mu \mathrm{m}$ and the SS substrate was $5000 \mu \mathrm{m}$. For comparison purposes, they are plotted in the same graph

with compressive stress (up to - $200 \mathrm{MPa}$ ), while the substrate has mostly compressive stresses acting on the surface $(-200$ to $-500 \mathrm{MPa})$ with a circular region in the center with tensile stress (150-200 MPa). Following $1.08 \mu \mathrm{s}$, the residual stress acting in the YSZ coating do not change significantly with the only exception of a small ring-like region with slightly higher tensile stress range (50-100 MPa). The residual stresses acting in the substrate surface are mostly compressive with the circular tensile stress region growing in magnitude as time progresses with the highest magnitude of around 500-600 MPa at the final time instant $(6 \mu \mathrm{s})$. There isn't a significant change in the magnitude for the single splat coating for the different
Fig. 9 Cross-sectional residual stress contour plots (in MPa) for the analysis performed for substrate without cooling for YSZ coating $(17.3 \mu \mathrm{m}$ thickness) on SS substrate (37.5 $\mu \mathrm{m}$ thickness) for particle impact velocity of $240 \mathrm{~m} / \mathrm{s}$. Tensile stresses are represented in color spectrum, and compressive stresses are represented in black color. Coating $(\mathrm{C})$ is represented in red box and substrate $(\mathrm{S})$ in black box (Color figure online)
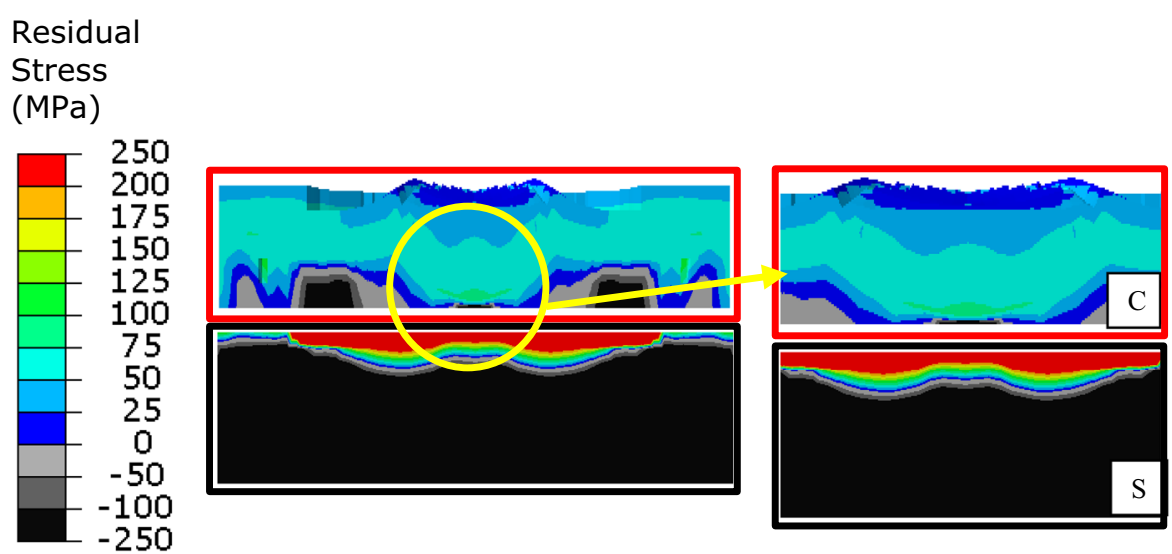

Cross-sectional view
Magnified cross-sectional view 
cases (Case A and Case B). However, it is seen that the nature of the stresses are highly transient for Case A while for Case B there isn't noticeable change throughout different time instants.

\section{Through-Thickness Residual Stresses For Single Particle}

The through-thickness residual stress profiles in the $\mathrm{XZ}$ plane (in-plane stress) for Case A and Case B are shown in Fig. 8(a) and (b), respectively, at different time intervals. For the ease of representation, the stresses are plotted for different time intervals post the spreading of the droplet. Two vertical axes are plotted to show the residual stresses on the particle and substrate separately. For time instant of $1.2 \mu$ s for Case A, the residual stress profile of the YSZ coating is compressive on the top surface and then gradually becomes tensile through the thickness. Following $1.2 \mu \mathrm{s}$, the residual stress acting in the coating is mostly tensile and the stresses are found to increase with each time instant. The maximum and minimum residual stress in the coating is 38 and $-3 \mathrm{MPa}$, respectively. At time instant of $1.2 \mu \mathrm{s}$, the residual stress acting in the substrate is compressive at the interface $(-150 \mathrm{MPa})$ and then has a sharp decrease through the thickness $(-400 \mathrm{MPa})$. Following that, the stress profile has a sharp increase to obtain tensile stress value of $50 \mathrm{MPa}$ and then a drop to achieve compressive stress of $-50 \mathrm{MPa}$. The stress profile then has minimum variations and is mostly tensile with stress range of 19-25 MPa. At the substrate interface, the stress value becomes higher with the increase in time instant but other than that the overall stress profile has minimum variation.

The through-thickness residual stress for Case B is shown in Fig. 8(b). The residual stresses acting within the coating are mostly tensile with a maximum stress of
$65 \mathrm{MPa}$. At time instant of $1.8 \mu \mathrm{s}$, the stress acting on the top surface is low tensile stress (10 MPa) and then reaches a maximum peak value of $40 \mathrm{MPa}$ followed by a dip through the thickness $(25 \mathrm{MPa})$. The coating stress profile for the following time instants have a similar behavior with the values being slightly different with the final time instant having the highest magnitude. The residual stress acting in the substrate is tensile at the interface and then becomes compressive which is then followed by a tensile peak. The highest tensile stress in the substrate (445 MPa) occurs at time instants 5.1 and $6 \mu$ s while the highest compressive stress (- $305 \mathrm{MPa})$ occurs at time instants of 1.8 and $2.7 \mu$ s. Comparing the behavior of Case A and Case B for coating stress profile, it is seen that they are quite similar in nature with the exception of higher stress values for Case B. Additionally, the compressive stress highest value is lower for Case B (about - $300 \mathrm{MPa}$ ) than Case A (- $409 \mathrm{MPa})$.

\section{Residual Stresses in Thick Coating Without Substrate Cooling}

A sequential impact of YSZ particles impacting SS substrate was carried out to obtain a thick coating. A total of 100 particles with an impact velocity of $240 \mathrm{~m} / \mathrm{s}$ was simulated using axisymmetric conditions to reduce computational time and a final thickness of $17.3 \mu \mathrm{m}$ was obtained. The reason for obtaining such a small thickness of the coating is due to the smaller mesh domain which caused the splashing of the coating outside the mesh domain due to the high impact velocity of the particle. Increasing the size of the mesh domain wouldn't aid in obtaining a thicker coating as in experimental methods the thermal spray gun is passed over a pre-determined path
Fig. 11 Cross-sectional residual stress contour plots (in $\mathrm{MPa}$ ) for the analysis performed for substrate with cooling for YSZ coating $(61.3 \mu \mathrm{m}$ thickness) on SS substrate (37.5 $\mu \mathrm{m}$ thickness) for particle impact velocity of $100 \mathrm{~m} / \mathrm{s}$. Tensile stresses are represented in color spectrum and compressive stresses are represented in black color. Coating $(\mathrm{C})$ is represented in red box and substrate (S) in black box (Color figure online)

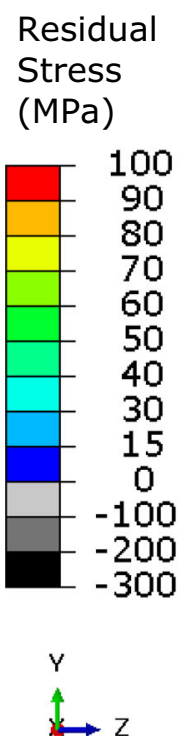

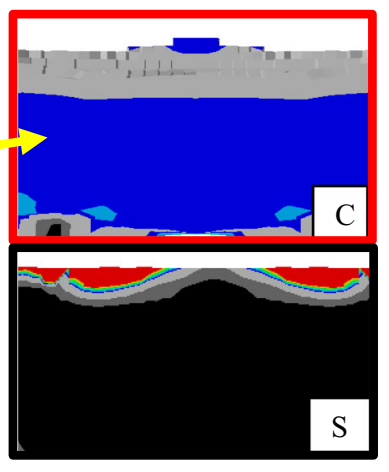

Cross-sectional view

Magnified cross-sectional view 


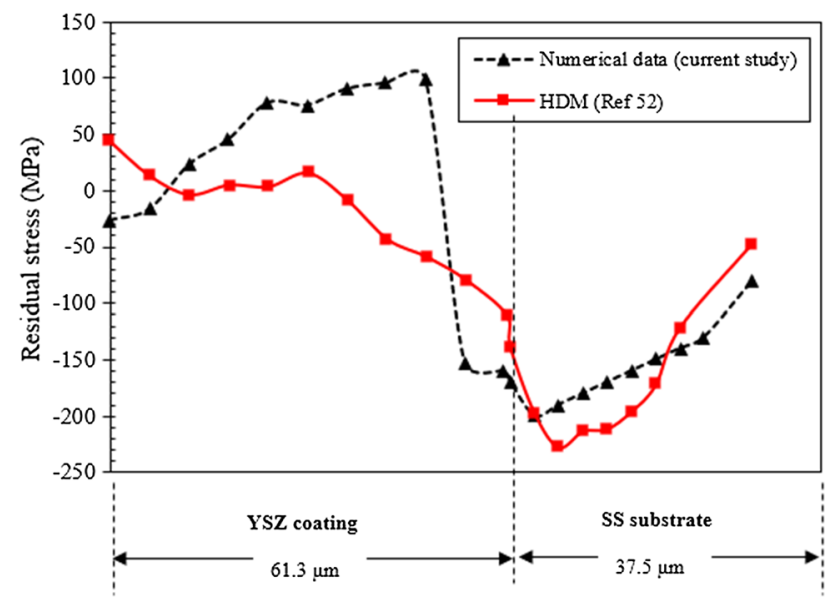

Fig. 12 Comparison of through-thickness residual stress distribution for YSZ coating (thickness $61.3 \mu \mathrm{m})$ on SS substrate $(37.5 \mu \mathrm{m})$ with substrate cooling obtained from the current study for impact velocity of $100 \mathrm{~m} / \mathrm{s}$ with the stress profile obtained by hole-drilling method (HDM) by Montay et al. (Ref 52). Note: The coating thickness of YSZ coating by Montay et al. was $590 \mu \mathrm{m}$ and the SS substrate was $5000 \mu \mathrm{m}$. For comparison purposes, they are plotted in the same graph

over the substrate. So, the molten particles impact on a solidified coating layer as opposed to impacting on a molten layer of coating in the numerical simulation. The final residual stress contours acting in the cross section of the coating and substrate obtained from the finite element package are shown in Fig. 9 for substrate without cooling. It is seen that the bulk of the coating experiences tensile stresses (90-230 MPa) with compressive stresses (up to - $250 \mathrm{MPa}$ ) occurring closer to the coating/substrate interface. The substrate experiences tensile stresses on the top surface with a maximum tensile stress range of 200-250 MPa occurring closer to the interface followed by a small region of low levels of tensile stress. The rest of the substrate has compressive stresses ( -50 to $-250 \mathrm{MPa}$ ). A magnified view of the coating/substrate system is also shown in Fig. 9. It is seen that there is a large variation in the magnitude and nature of stresses in the coating and substrate. The through-thickness residual stress distribution of the thick YSZ coating and SS substrate is shown in Fig. 10. The residual stress measurements were performed farther from the surfaces on which the symmetric boundary conditions were given as it was seen that they influenced the residual stress profiles. The residual stress acting on the YSZ coating is mostly tensile with stress range of $100 \mathrm{MPa}$ to $250 \mathrm{MPa}$. The residual stress acting on the substrate is tensile closer to the interface and then becomes compressive through the thickness with a maximum stress of - $195 \mathrm{MPa}$. The residual stress distribution obtained by Montay et al. (Ref 52) using incremental hole-drilling method is also plotted for comparison in Fig. 10. The YSZ coating and SS substrate used in (Ref 52) were about
$590 \mu \mathrm{m}$ and $5 \mathrm{~mm}$ and is plotted in the same graph for the sake of comparison with the numerical data from the current study. The results indicate that the nature and magnitude of residual stresses within the SS substrate is comparable for the current numerical data and the holedrilling method (HDM).

Differences were observed for the YSZ coating for the numerical data and HDM. The numerical data predicted the stresses within the coating to be mostly tensile while the hole-drilling method predicted it to be tensile on the surface and then through thickness compressive. The possible explanation for this residual stress behavior in the substrate is due to the influence of measurement technique on the residual stress profile. HDM is known to affect the residual stress behavior by the formation of micro-cracks in the vicinity of the hole (Ref 4). Recently, neutron diffraction measurement techniques have widely been used due to their non-destructive and high penetration capabilities and a comparative study of neutron diffraction and hole-drilling method was carried out by Ahmed et al. (Ref 4). It was concluded that the hole-drilling method predicts residual stress in the top layer of the coating reasonably well but through the thickness there is a significant difference in these experimental values of the residual stresses. The residual stresses predicted by HDM are macro-stresses. Neutron diffraction (ND) techniques are much more effective in predicting residual stresses and the profile obtained from ND technique can be compared with stress profile from numerical data. However, there is very limited work available on neutron diffraction for YSZ and SS combination.

\section{Residual Stresses in Thick Coating with Substrate Cooling}

The residual stress analysis was performed with the substrate cooling. A total of 100 particles with an impact velocity of $100 \mathrm{~m} / \mathrm{s}$ was simulated using axisymmetric conditions to reduce computational time and a final thickness of $61.3 \mu \mathrm{m}$ was obtained. The preheated temperature $(423 \mathrm{~K})$ to the substrate was applied only to the top of the substrate, and the rest of the substrate was given a lower temperature $(298 \mathrm{~K})$ in the numerical model to mimic the cooling of the substrate similar to experimental conditions. This was done to enhance the cooling of the substrate since the substrate for the model described in "Residual Stresses in Thick Coating Without Substrate Cooling" section had poor cooling effects. The final residual stress contours acting in the cross section of the coating and substrate obtained from the finite element package are shown in Fig. 11 for the case of substrate with cooling. The coating experiences mostly compressive stresses on the top surface with the middle region experiencing tensile stresses followed by the lower region (closer 
Table 8 Calculated thermal stress (analytical method) for YSZ coating and SS substrate for different coating thickness using Eq 11

\begin{tabular}{llcllccc}
\hline No. & Material & $\begin{array}{c}\text { Young's modulus } \\
(\mathrm{GPa})\end{array}$ & $\begin{array}{c}\text { Poisson's } \\
\text { ratio }\end{array}$ & CTE $\left(\mathrm{K}^{-1}\right)$ & $\begin{array}{c}\text { Thickness } \\
(\mu \mathrm{m})\end{array}$ & $\begin{array}{c}\text { Temperature change } \\
(\mathrm{K})\end{array}$ & $\begin{array}{c}\text { Calculated thermal stress } \\
(\mathrm{MPa})\end{array}$ \\
\hline 1 & YSZ & $E_{\mathrm{c}}=241$ & $v_{\mathrm{c}}=0.32$ & $\alpha_{\mathrm{c}}=6.3 \times 10^{-6}$ & $t_{\mathrm{c}}=2.14$ & $\Delta T=2827$ & $\sigma_{\mathrm{c}}=8514$ \\
& $\mathrm{SS}$ & $E_{\mathrm{s}}=200$ & $v_{\mathrm{s}}=0.3$ & $\alpha_{\mathrm{s}}=1.54 \times 10^{-5}$ & $t_{\mathrm{s}}=37.5$ & & $\sigma_{\mathrm{s}}=-485$ \\
2 & YSZ & $E_{\mathrm{c}}=241$ & $v_{\mathrm{c}}=0.32$ & $\alpha_{\mathrm{c}}=6.3 \times 10^{-6}$ & $t_{\mathrm{c}}=17.3$ & $\Delta T=2827$ & $\sigma_{\mathrm{c}}=5798$ \\
& $\mathrm{SS}$ & $E_{\mathrm{s}}=200$ & $v_{\mathrm{s}}=0.3$ & $\alpha_{\mathrm{s}}=1.54 \times 10^{-5}$ & $t_{\mathrm{s}}=37.5$ & & $\sigma_{\mathrm{s}}=-2675$ \\
3 & YSZ & $E_{\mathrm{c}}=241$ & $v_{\mathrm{c}}=0.32$ & $\alpha_{\mathrm{c}}=6.3 \times 10^{-6}$ & $t_{\mathrm{c}}=61.3$ & $\Delta T=2827$ & $\sigma_{\mathrm{c}}=3011$ \\
& $\mathrm{SS}$ & $E_{\mathrm{s}}=200$ & $v_{\mathrm{s}}=0.3$ & $\alpha_{\mathrm{s}}=1.54 \times 10^{-5}$ & $t_{\mathrm{s}}=37.5$ & & $\sigma_{\mathrm{s}}=-4922$ \\
\hline
\end{tabular}

Subscripts " $c$ " and " $s$ " stand for coating and substrate, respectively, + ve: tensile, - ve: compressive

to interface) experiencing compressive stresses. The substrate mostly has small regions of tensile stresses closer to the interface while the rest of the substrate experiences compressive stresses. A magnified view of the coating/substrate system is also shown in Fig. 11. It is seen that there is a large variation in the magnitude and nature of stresses in the coating and substrate. Comparing the magnified view, it is seen that the coating has a mixture of compressive and tensile stress for both substrate with cooling (Fig. 11) and for substrate without cooling (Fig. 9). The substrate is seen to have compressive stresses closer to the center for substrate with cooling (Fig. 11), while there are high tensile stresses for substrate without cooling (Fig. 9).

The through-thickness residual stress profile for YSZ coating and SS substrate is shown in Fig. 12. The residual stress acting in the YSZ coating is compressive on the top of the coating ( $-27 \mathrm{MPa}$ ) and then becomes tensile (100 MPa) through the thickness. The residual stress profile then becomes compressive closer to the substrate/coating interface $(-170 \mathrm{MPa})$. The substrate consists of mostly compressive stress $(-197 \mathrm{MPa})$, and the magnitude of stress reduces through the thickness. The stress profile obtained by Montay et al. (Ref 52) is also plotted in Fig. 12 for comparison. It is seen that the numerical study predicted the coating residual stress to be mostly tensile while the HDM predicted it to be mostly compressive. The substrate residual stress profile obtained in the current study is comparable to the HDM profile. It is seen that the numerical study predicted the coating residual stress (with and without cooling, "Residual Stresses in Thick Coating Without Substrate Cooling" and "Residual Stresses in Thick Coating with Substrate Cooling" sections) to be tensile while the HDM results (Ref 52) predicted it to be compressive. This can be attributed to the influence of measurement technique as discussed above. Another possible explanation for the different nature of the residual stress with HDM (Ref 52) is the different ratio of thickness of coating to substrate. The future research would consist of following the same thickness of the substrate/coating or following the similar coating to substrate thickness ratio and spray parameters like the experiment for quantitative validation.

\section{Comparison with Coefficient of Thermal Expansion Model}

The macro-residual stresses obtained from numerical simulation were compared with the coefficient of thermal expansion model for a two-layer system. Residual stresses due to thermal expansion mismatch stress in a two-layer system could be based on the following equation assuming that the coefficient of thermal expansion (CTE) does not vary with $\Delta T(\operatorname{Ref} 77,78)$ :

$\sigma_{C}=\frac{1}{t_{C}}\left[\frac{\left(\alpha_{S}-\alpha_{C}\right) \cdot \Delta T}{\frac{1-v_{C}}{t_{C} E_{C}}+\frac{1-v_{S}}{t_{S} E_{S}}}\right]$

where $\sigma, E, v, \alpha$ and $\Delta T$ are thermal stress, Young's modulus, Poisson's ratio, CTE and temperature change, respectively. The subscripts " $c$ " and " $s$ " are properties of coating and substrate, respectively. Upon the YSZ particle impacting the substrate, the particle temperature is taken as $3250 \mathrm{~K}$. The temperature change $\Delta T$ in Eq 11 was taken as $2827 \mathrm{~K}$, as it was assumed that the particle cools down to the temperature of the substrate, $423 \mathrm{~K}$. The thermal stresses calculated using Eq 11 for the YSZ coating and SS substrate for three distinct coating thicknesses are shown in Table 8. It is seen that the stresses calculated using analytical methods give high thermal stress values. It is also seen that the thermal stresses acting in the coating reduces as the thickness increases which is likely not seen in the experimental data. The stresses calculated using Eq 11 are inaccurate since it assumes perfect bonding between the particle and substrate (Ref 4, 79). Phase change of the materials (Ref 80) and the variation of Young's modulus, Poisson's ratio and CTE with temperature are not considered. 


\section{Conclusion}

A numerical model of residual stress evolution is presented for single and multiple splats of YSZ coating on SS substrate. The model is in reasonable agreement with the previously reported experimental (Ref 52, 72) and numerical investigations (Ref 58). The following were the main conclusions drawn from the current study:

1. The final splat shape obtained highly depends on the thermal conductance between the particle and substrate. Higher thermal conductance leads to the formation of fingers and leads to splashing.

2. For single particle impact, the thermal conductance used in the model influences the through-thickness residual stresses obtained in the coating and substrate. The nature of the stresses is same, but the magnitude obtained for lower conductance is slightly higher.

3. For multiple impact model without substrate cooling, the residual stress profile in the coating is only tensile which is balanced by compressive stresses in the substrate.

4. For multiple impact model with substrate cooling, the residual stress in the coating is low compressive on the top surface and then becomes tensile while the substrate is mostly compressive.

Open Access This article is distributed under the terms of the Creative Commons Attribution 4.0 International License (http://crea tivecommons.org/licenses/by/4.0/), which permits unrestricted use, distribution, and reproduction in any medium, provided you give appropriate credit to the original author(s) and the source, provide a link to the Creative Commons license, and indicate if changes were made.

\section{References}

1. P.L. Fauchais, J.V.R. Heberlein, and M.I. Boulos, Thermal Spray Fundamentals, Springer, Berlin, 2014, https://doi.org/10.1007/ 978-0-387-68991-3

2. M. Zirari, A. Abdellah El-Hadj, and N. Bacha, Numerical Analysis of Partially Molten Splat during Thermal Spray Process Using the Finite Element Method, Appl. Surf. Sci., 2010, 256(11), p 3581-3585. https://doi.org/10.1016/j.apsusc.2009.12.158

3. Y. Kumar and S. Kumar, Numerical Modeling of Impact and Solidification of a Molten Alloy Droplet on a Substrate, $A d v$. Mater. Form. Join., 2015. https://doi.org/10.1007/978-81-3222355-9

4. R. Ahmed, M.E. Fitzpatrick, and N.H. Faisal, A Comparison of Neutron Diffraction and Hole-Drilling Residual Strain Measurements in Thermally Sprayed Coatings, Surf. Coat. Technol., 2012, 206(19-20), p 4180-4185

5. O. Ali, R. Ahmed, N.H. Faisal, N.M. Alanazi, L.M. Berger, A. Kaiser, F.L. Toma, E.K. Polychroniadis, M. Sall, Y.O. Elakwah, and M.F.A. Goosen, Influence of Post-treatment on the Microstructural and Tribomechanical Properties of Suspension
Thermally Sprayed WC-12 wt\%Co Nanocomposite Coatings, Tribol. Lett., 2017, 65(2), p 1-27

6. N.H. Faisal, R. Ahmed, S.P. Katikaneni, S. Souentie, and M.F.A. Goosen, Development of Plasma-Sprayed Molybdenum CarbideBased Anode Layers with Various Metal Oxides for SOFC, $J$. Therm. Spray Technol., 2015, 24(8), p 1415-1428

7. R. Ahmed, O. Ali, N.H. Faisal, N.M. Al-Anazi, S. Al-Mutairi, F.L. Toma, L.M. Berger, A. Potthoff, and M.F.A. Goosen, Sliding Wear Investigation of Suspension Sprayed WC-Co Nanocomposite Coatings, Wear, 2015, 322-323, p 133-150

8. W. Ramsden, The Royal Society is Collaborating with JSTOR to Digitize, Preserve, and Extend Access to Proceedings of the Royal Society of London ${ }^{\circledR}, 1903,72$, p 156-164, Www.jstor.org. Accessed 12 Dec 2017

9. F.H. Harlow and J.P. Shannon, The Splash of a Liquid Drop, J. Appl. Phys., 1967, 38(10), p 3855-3866

10. S. Yin, X.F. Wang, B.P. Xu, and W.Y. Li, Examination on the Calculation Method for Modeling the Multi-Particle Impact Process in Cold Spraying, J. Therm. Spray Technol., 2010, 19(5), p 1032-1041

11. M. Yu, W.Y. Li, F.F. Wang, and H.L. Liao, Finite Element Simulation of Impacting Behavior of Particles in Cold Spraying by Eulerian Approach, J. Therm. Spray Technol., 2012, 21(3-4), p 745-752

12. Y. Li, X. Wang, S. Yin, and S. Xu, Influence of Particle Initial Temperature on High Velocity Impact Process in Cold Spraying, Procedia Environ. Sci., 2012, https://doi.org/10.1016/j.proenv. 2012.01.281

13. G. Bae, Y. Xiong, S. Kumar, K. Kang, and C. Lee, General Aspects of Interface Bonding in Kinetic Sprayed Coatings, Acta Mater., 2008, 56(17), p 4858-4868

14. B. Yildirim, H. Fukanuma, T. Ando, A. Gouldstone, and S. Müftü, A Numerical Investigation Into Cold Spray Bonding Processes, J. Tribol., 2014, 137(1), p 11102

15. M. Zhang, H. Zhang, and L. Zheng, Numerical Investigation of Substrate Melting and Deformation During Thermal Spray Coating by SPH Method, Plasma Chem. Plasma Process., 2009, 29(1), p 55-68

16. M.Y. Zhang, H. Zhang, and L.L. Zheng, Simulation of Droplet Spreading, Splashing and Solidification Using Smoothed Particle Hydrodynamics Method, Int. J. Heat Mass Transf., 2008, 51(1314), p 3410-3419

17. M. Zhang, H. Zhang, and L. Zheng, Application of Smoothed Particle Hydrodynamics Method to Free Surface and Solidification Problems, Numer. Heat Transf. Part A Appl., 2007, 52(4), p 299-314. https://doi.org/10.1080/00397910601150007

18. S. Kamnis and S. Gu, Numerical Modelling of Droplet Impingement, J. Phys. D Appl. Phys., 2005, 38(38), p 3664-3673. https://doi.org/10.1088/0022-3727/38/19/015

19. S. Shakeri and S. Chandra, Splashing of Molten Tin Droplets on a Rough Steel Surface, Int. J. Heat Mass Transf., 2002, 45(23), p 4561-4575

20. S. Kamnis, S. Gu, T.J. Lu, and C. Chen, Numerical Modelling of Sequential Droplet Impingements, J. Phys. D. Appl. Phys., 2008, 41(16), p 165-303. https://doi.org/10.1088/0022-3727/41/16/ 165303

21. M. Pasandideh-Fard, S. Chandra, and J. Mostaghimi, A ThreeDimensional Model of Droplet Impact and Solidification, Int. J. Heat Mass Transf., 2002, 45(11), p 2229-2242

22. R.K. Shukla, S.K. Yadav, M.H. Shete, and A. Kumar, Numerical Modeling of Impact and Solidification of a Molten Alloy Droplet on a Substrate, Adv. Mater. Form. Join., 2015, https://doi.org/10. 1007/978-81-322-2355-9

23. M.E. Aalami-aleagha, S. Feli, and A.R. Eivani, FEM Simulation of Splatting of a Molten Metal Droplet in Thermal Spray Coating, 
Comput. Mater. Sci., 2010, 48(1), p 65-70. https://doi.org/10. 1016/j.commatsci.2009.12.002

24. M. Bussmann, S. Chandra, and J. Mostaghimi, Modeling the Splash of a Droplet Impacting a Solid Surface, Phys. Fluids, 2000, 12(12), p 3121-3132

25. M. Bussmann, J. Mostaghimi, and S. Chandra, On a Three-Dimensional Volume Tracking Model of Droplet Impact, Phys. Fluids, 1999, 11(6), p 1406-1417. https://doi.org/10.1063/1. 870005

26. M. Pasandideh-Fard, R. Bhola, S. Chandra, and J. Mostaghimi, Deposition of Tin Droplets on a Steel Plate: Simulations and Experiments, Int. J. Heat Mass Transf., 1998, 41, p 2929-2945

27. M. Pasandideh-Fard, V. Pershin, S. Chandra, and J. Mostaghimi, Splat Shapes in a Thermal Spray Coating Process: Simulations and Experiments, J. Therm. Spray Technol., 2002, 11(2), p 206217. https://doi.org/10.1361/105996302770348862

28. M. Xue, Y. Heichal, S. Chandra, and J. Mostaghimi, Modeling the Impact of a Molten Metal Droplet on a Solid Surface Using Variable Interfacial Thermal Contact Resistance, J. Mater. Sci., 2007, 42(1), p 9-18

29. K. Khor and Y. Gu, Effects of Residual Stress on the Performance of Plasma Sprayed Functionally Graded $\mathrm{ZrO} 2 / \mathrm{NiCoCrA1Y}$ Coatings, Mater. Sci. Eng. A, 2000, 277(1-2), p 64-76. https://doi. org/10.1016/S0921-5093(99)00565-1

30. V. Teixeira, M. Andritschky, W. Fischer, H.P. Buchkremer, and D. Stover, Effects of Deposition Temperature and Thermal Cycling on Residual Stress State in Zirconia-Based Thermal Barrier Coatings, Surf. Coat. Technol., 1999, 120, p 103-111

31. Z. Xue, A.G. Evans, and J.W. Hutchinson, Delamination Susceptibility of Coatings Under High Thermal Flux, J. Appl. Mech., 2009, 76(4), p 41008

32. P. Araujo, D. Chicot, M. Staia, and J. Lesage, Residual Stresses and Adhesion of Thermal Spray Coatings, Surf. Eng., 2005, 21(1), p 35-40. https://doi.org/10.1179/174329405X30020

33. T.W. Clyne and S.C. Gill, Residual Stresses in Thermal Spray Coatings and Their Effect on Interfacial Adhesion: A Review of Recent Work, J. Therm. Spray. Technol., 1996, 5(4), p 401. https://doi.org/10.1007/bf02645271

34. R. Ahmed, N.H. Faisal, A.M. Paradowska, and M.E. Fitzpatrick, Residual Strain and Fracture Response of $\mathrm{Al}_{2} \mathrm{O}_{3}$ Coatings Deposited via APS and HVOF Techniques, J. Therm. Spray Technol., 2012, 21, p 23-40

35. N.H. Faisal, R. Ahmed, A.K. Prathuru, S.P. Katikaneni, M.F.A. Goosen, and S.Y. Zhang, Neutron Diffraction Residual Strain Measurements of Molybdenum Carbide-Based Solid Oxide Fuel Cell Anode Layers with Metal Oxides on Hastelloy X, Exp. Mech., 2017, 58, p 1-19

36. S. Kuroda, T. Dendo, and S. Kitahara, Quenching Stress in Plasma Sprayed Coatings and Its Correlation with the Deposit Microstructure, J. Therm. Spray Technol., 1995, 4(1), p 75-84

37. J. Matejicek, S. Sampath, D. Gilmore, and R. Neiser, In Situ Measurement of Residual Stresses and Elastic Moduli in Thermal Sprayed Coatings Part 2: Processing Effects on Properties of Mo Coatings, Acta Mater., 2003, 51(3), p 873-885

38. M.H. Staia, E. Ramos, A. Carrasquero, A. Roman, J. Lesage, D. Chicot, and G. Mesmacque, Effect of Substrate Roughness Induced by Grit Blasting upon Adhesion of WC-17\% Co Thermal Sprayed Coatings, Thin Solid Films, 2000, 377-378, p 657-664

39. R. Gadow, M.J. Riegert-Escribano, and M. Buchmann, Residual Stress Analysis in Thermally Sprayed Layer Composites, Using the Hole Milling and Drilling Method, J. Therm. Spray Technol., 2005, 14(1), p 100-108

40. A.A. Abubakar, A.F.M. Arif, K.S. Al-Athel, S.S. Akhtar, and J. Mostaghimi, Modeling Residual Stress Development in Thermal Spray Coatings: Current Status and Way Forward, J. Therm. Spray Technol., 2017, 26(6), p 1115-1145
41. O.P. Oladijo, A.M. Venter, L.A. Cornish, and N. Sacks, Surface \& Coatings Technology X-ray Diffraction Measurement of Residual Stress in WC-Co Thermally Sprayed Coatings onto Metal Substrates, Surf. Coat. Technol., 2012, 206(23), p 47254729. https://doi.org/10.1016/j.surfcoat.2012.01.044

42. B.S. Yilbas and A.F.M. Arif, Residual Stress Analysis for HVOF Diamalloy 1005 Coating on Ti-6Al-4V Alloy, Surf. Coat. Technol., 2007, 202(3), p 559-568

43. T.C. Totemeier and J.K. Wright, Residual Stress Determination in Thermally Sprayed Coatings-A Comparison of Curvature Models and X-ray Techniques, Surf. Coat. Technol., 2006, 200(12-13), p 3955-3962

44. Y.C. Yang and E. Chang, Measurements of Residual Stresses in Plasma-Sprayed Hydroxyapatite Coatings on Titanium Alloy, Surf. Coat. Technol., 2005, 190(1), p 122-131

45. J. Pina, A. Dias, and J. Lebrun, Study by X-ray Diffraction and Mechanical Analysis of the Residual Stress Generation During Thermal Spraying, Mater. Sci. Eng. A, 2003, 347(1-2), p 21-31. https://doi.org/10.1016/S0921-5093(02)00580-4

46. O. Kesler, J. Matejicek, S. Sampath, S. Suresh, T. GnaeupelHerold, P.C. Brand, and H.J. Prask, Measurement of Residual Stress in Plasma-Sprayed Metallic, Ceramic and Composite Coatings, Mater. Sci. Eng. A, 1998, 257(2), p 215-224

47. J. Matejícek, S. Sampath, and J. Dubsky, X-ray Residual Stress Measurement in Metallic and Ceramic Plasma Sprayed Coatings, J. Therm. Spray Technol., 1998, 7(4), p 489-496

48. C. Lyphout, P. Nylén, A. Manescu, and T. Pirling, Residual Stresses Distribution Through Thick HVOF Sprayed Inconel 718 Coatings, J. Therm. Spray Technol., 2008, 17, p 915-923

49. G.G. Stoney, The Tension of Metallic Films Deposited by Electrolysis, Proc. R. Soc. Lond. Ser. A Contain. Pap. Math. Phys. Character, 1909, 82, p 172-175

50. A. Brenner and S. Senderoff, A Spiral Contractometer for Measuring Stress in Electrodeposits, J. Res. Natl. Bur. Stand., 1949, 42(February), p 89

51. M. Mutter, G. Mauer, R. Mucke, R. Vaßen, H.C. Back, and J. Gibmeier, Investigations on the Initial Stress Evolution During Atmospheric Plasma Spraying of YSZ by In Situ Curvature Measurement, J. Therm. Spray Technol., 2016, 25(4), p 672-683

52. G. Montay, A. Cherouat, J. Lu, N. Baradel, and L. Bianchi, Development of the High-Precision Incremental-Step Hole-Drilling Method for the Study of Residual Stress in Multi-layer Materials: Influence of Temperature and Substrate on $\mathrm{ZrO} 2-$ Y2O38 Wt\% Coatings, Surf. Coat. Technol., 2002, 155(2-3), p $152-160$

53. B.W.M. Levit and I. Grimberg, Residual Stresses in Ceramic Plasma-Sprayed Thermal Barrier Coatings: Measurement and Calculation, Mater. Sci. Eng. A, 1996, 5093(95), p 30-38

54. P. Scardi, M. Leoni, and L. Bertamini, Residual Stresses in Plasma Sprayed Partially Stabilised Zirconia TBCs: Influence of the Deposition Temperature, Thin Solid Films, 1996, 278, p 96-103

55. X. Wang and P. Xiao, Residual Stresses and Constrained Sintering of $\mathrm{YSZ} / \mathrm{Al}_{2} \mathrm{O}_{3}$ composite Coatings, Acta Mater., 2004, 52(9), p 2591-2603

56. J. Zhu, W. Chen, and H. Xie, Simulation of Residual Stresses and Their Effects on Thermal Barrier Coating Systems Using Finite Element Method, Sci. China Phys. Mech. Astron., 2015, 58(3), p 1-10. https://doi.org/10.1007/s11433-014-5541-y

57. M. Ranjbar-Far, J. Absi, G. Mariaux, and S. Shahidi, Modeling of the Residual Stresses and Their Effects on the TBC System after Thermal Cycling Using Finite Element Method, Ceram. Mater., 2010, 62(3), p 275-279

58. Z. Zhu, S. Kamnis, and S. Gu, Numerical Study of Molten and Semi-molten Ceramic Impingement by Using Coupled Eulerian and Lagrangian Method, Acta Mater., 2015, 90, p 77-87. https:// doi.org/10.1016/j.actamat.2015.02.010 
59. Abaqus Analysis User's Manual, ABAQUS 2016 HTML Documentation, Dassault Systems, 2016, http://50.16.225.63/v2016/. Accessed 17 Jan 2018

60. H. Chen, W.H. Tang, X.W. Ran, M.J. Zhang, and Z.H. Xu, Measurement of the Mie-Gruneisen Equation of State for Polyimide, Chin. Sci. Bull., 2013, 58(6), p 585-588

61. G. Mie, Zur Kinetischen Theorie Der Einatomigen Korper, Ann. Phys., 1903, 316(8), p 657-697

62. E. Grüneisen, Theorie Des Festen Zustandes Einatomiger Elemente, Ann. Phys., 1912, 344(12), p 257-306

63. K.-M. Shyue, A Fluid-Mixture Type Algorithm for Compressible Multicomponent Flow with Mie-Grüneisen Equation of State, $J$. Comput. Phys., 2001, 171(2), p 678-707. https://doi.org/10.1006/ jcph.2001.6801

64. M.H. Rice, R.G. McQueen, and J.M. Walsh, Compression of Solids by Strong Shock Waves, Solid State Phys. Adv. Res. Appl., 1958, 6(C), p 1-63

65. M.L. Wilkins, Computer Simulation of Dynamic Phenomena, Scientific Computation Springer, Berlin, 1999

66. A.L. Ruoff, Linear Shock-Velocity-Particle-Velocity Relationship, J. Appl. Phys., 1967, 38(13), p 4976-4980

67. T. Mashimo, A. Nakamura, M. Nishida, S. Matsuzaki, K. Kusaba, K. Fukuoka, and Y. Syono, Anomalous Shock Compression Behavior of Yttria-Doped Tetragonal Zirconia, J. Appl. Phys., 1995, 77(10), p 5069-5076

68. T. Mashimo, A. Nakamura, M. Kodama, K. Kusaba, K. Fukuoka, and Y. Syono, Yielding and Phase Transition under Shock Compression of Yttria-Doped Cubic Zirconia Single Crystal and Polycrystal, J. Appl. Phys., 1995, 77(10), p 5060-5068

69. G.R. Johnson and W.H. Cook, Fracture Characteristics of Three Metals Subjected to Various Strains, Strain Rates, Temperatures and Pressures, Eng. Fract. Mech., 1985, 21(1), p 31-48

70. G.R. Johnson and W.H. Cook, A Constitutive Model and Data for Metals Subjected to Large Strains, High Strain Rates and High Temperatures, in 7th International Symposium on Ballistics, 1983, p 541-547.

71. H. Tabbara and S. Gu, Numerical Study of Semi-molten Droplet Impingement, Appl. Phys. A Mater. Sci. Process., 2011, 104(4), p 1011-1019
72. M. Vardelle, A. Vardelle, A.C. Leger, P. Fauchais, and D. Gobin, Influence of Particle Parameters at Impact on Splat Formation and Solidification in Plasma Spraying Processes, J. Therm. Spray Technol., 1995, 4(1), p 50-58

73. K. Shinoda, Y. Kojima, and T. Yoshida, In Situ Measurement System for Deformation and Solidification Phenomena of YttriaStabilized Zirconia Droplets Impinging on Quartz Glass Substrate Under Plasma-Spraying Conditions, J. Therm. Spray Technol., 2005, 14(4), p 511-517

74. K. Shinoda and H. Murakami, Splat Morphology of Yttria-Stabilized Zirconia Droplet Deposited via Hybrid Plasma Spraying, J. Therm. Spray Technol., 2010, 19(3), p 602610

75. R. Dhiman, A.G. McDonald, and S. Chandra, Predicting Splat Morphology in a Thermal Spray Process, Surf. Coat. Technol., 2007, 201(18), p 7789-7801

76. V. Pershin, M. Lufitha, S. Chandra, and J. Mostaghimi, Effect of Substrate Temperature on Adhesion Strength of Plasma-Sprayed Nickel Coatings, J. Therm. Spray Technol., 2003, 12(3), p 370376

77. M. Ohring, Materials Science of Thin Films-Deposition \& Structure, Mater. Sci., 2001, https://doi.org/10.1016/b978012524975-1/50010-0

78. A.J. Mcginnis, T.R. Watkins, and K. Jagannadham, Residual Stresses in a Multilayer System of Coatings, JCPDS Int. Cent. Diffr. Data 1999, 1993, 41(C), p 443-454

79. R. Ahmed, H. Yu, S. Stewart, L. Edwards, and J.R. Santisteban, Residual Strain Measurements in Thermal Spray Cermet Coatings via Neutron Diffraction, J. Tribol., 2007, 129(2), p 411. https://doi.org/10.1115/1.2647503

80. N.H. Faisal, R. Ahmed, A.K. Prathuru, S.P. Katikaneni, M.F.A. Goosen, and S.Y. Zhang, Neutron Diffraction Residual Strain Measurements of Molybdenum Carbide-Based Solid Oxide Fuel Cell Anode Layers with Metal Oxides on Hastelloy X, Exp. Mech., 2018, 58(4), p 585-603. https://doi.org/10.1007/s11340017-0298-7

Publisher's Note Springer Nature remains neutral with regard to jurisdictional claims in published maps and institutional affiliations. 